\title{
A new bivariate risk classifier for flood management considering hazard and socio- economic dimensions
}

Mohanty, Mohit Prakash; Vittal, H; Yadav, Vinay; Ghosh, Subimal; Rao, Goru Srinivasa; Karmakar, Subhankar

Published in:

Journal of Environmental Management

Link to article, DOI:

10.1016/j.jenvman.2019.109733

Publication date:

2020

Document Version

Peer reviewed version

Link back to DTU Orbit

Citation (APA):

Mohanty, M. P., Vittal, H., Yadav, V., Ghosh, S., Rao, G. S., \& Karmakar, S. (2020). A new bivariate risk classifier for flood management considering hazard and socio-economic dimensions. Journal of Environmental Management, 255, [109733]. https://doi.org/10.1016/j.jenvman.2019.109733

\section{General rights}

Copyright and moral rights for the publications made accessible in the public portal are retained by the authors and/or other copyright owners and it is a condition of accessing publications that users recognise and abide by the legal requirements associated with these rights.

- Users may download and print one copy of any publication from the public portal for the purpose of private study or research.

- You may not further distribute the material or use it for any profit-making activity or commercial gain

- You may freely distribute the URL identifying the publication in the public portal 
3 Mohit Prakash Mohanty ${ }^{1}$, Vittal $\mathrm{H}^{1,2}$, Vinay Yadav $^{1,3}$, Subimal Ghosh ${ }^{4,5,6}$, Goru Srinivasa

$4 \quad \mathrm{Rao}^{7}$, Subhankar Karmakar ${ }^{1,5,6^{*}}$

$5{ }^{1}$ Environmental Science and Engineering Department, Indian Institute of Technology Bombay,

6 Mumbai-400076, India

$7 \quad{ }^{2}$ IIHR-Hydroscience \& Engineering, The University of Iowa, Iowa City, Iowa 52242-1585,

8 USA

$9{ }^{3}$ Department of Management Engineering, Technical University of Denmark, 2800 Lyngby, 10

Denmark

${ }^{4}$ Department of Civil Engineering, Indian Institute of Technology Bombay, Mumbai-400076, India

${ }^{5}$ Interdisciplinary Program in Climate Studies, Indian Institute of Technology Bombay, Mumbai-400076, India

${ }^{6}$ Centre for Urban Science and Engineering, Indian Institute of Technology Bombay, Mumbai400076, India

7Regional Remote Sensing Centre-East, National Remote Sensing Centre, Indian Space Research Organization (ISRO), Kolkata-700156, India

*Corresponding author at: Environmental Science and Engineering Department, Indian Institute of Technology Bombay, Mumbai 400076, India

E-mail address: skarmakar@iitb.ac.in (S. Karmakar)

URL: http://www.cese.iitb.ac.in/people/facinfo.php?id=skarmakar (S. Karmakar)

\section{Declarations of interest: none}


Identification of flood-risk dynamics is pivotal for refurbishing the existing and future flood-

management options. The present study quantifies the marginal and compound contributions of hazard and vulnerability to flood-risk through an innovative concept of Risk-classifier, designed in the form of a $5 \times 5$ choropleth. The proposed framework is demonstrated at the finest administrative scale of village-level over Jagatsinghpur district in Mahanadi River basin, Odisha (India) for two-time frames: Scenario-I (1970-2011) and Scenario-II (1970-2001). An increase in high and very high hazard and vulnerable villages is noticed in Scenario-I, the majority of them lying in the coastal stretches (S-E region) and adjoining flood plains of Mahanadi River (N-W region). Scenario-I is characterized by the majority of hazard-driven and compound (both hazard and vulnerability) risk villages, while Scenario II is characterized by a majority of vulnerability driven-risk villages. For the vulnerability-driven risk villages, rigorous enforcement of policies and mitigation schemes are recommended, while for hazarddriven risk villages, enhancement of structural measures and flood-plain zoning should be exercised. Such exhaustive flood-risk information may serve as a valuable cartographic product for the civic authorities and stakeholders and help in prioritizing flood mitigation actions for improved environmental planning and management.

Keywords: choropleth; decadal change; environmental planning and management; flood risk; hazard; socio-economic vulnerability

\section{Highlights}

- A new Risk Classifier to quantify flood risk at the finest administrative scale

- Flood hazard is obtained through robust hydrodynamic flood model simulations

- Socio-economic vulnerability is derived through a robust indicator based DEA method

- Risk classifier identifies marginal and compound impact of hazard and vulnerability

- Improved risk identification shells out focused flood-management strategies 


$\begin{array}{ll}\text { 1D } & \text { One dimensional flood model } \\ \text { 2D } & \text { Two dimensional flood model } \\ \text { CAO } & \text { Combined Averaging Optimization } \\ \text { CO } & \text { Complete Optimization } \\ d & \text { Flood water depth } \\ f & \text { Velocity of flood water } \\ D & \text { Rainfall duration } \\ \text { DEA } & \text { Data Envelopment Analysis } \\ \text { DEM } & \text { Digital Elevation Model } \\ \text { DMU } & \text { Decision Making Unit } \\ \text { G-H } & \text { Gumbel-Hougaard copula } \\ \text { GEV } & \text { Generalized Extreme Value } \\ \text { GPD } & \text { General Pareto Distribution } \\ h & \text { Nonparametric kernel bandwidth } \\ \mathcal{H} & \text { Flood hazard } \\ j & \text { Village } \\ \mathcal{v} & \text { Socio-economic vulnerability } \\ \text { PCA } & \text { Principal Components Analysis } \\ \text { PC } & \text { Principal Component } \\ \mathcal{R} & \text { Flood risk } \\ \mathcal{R D} \mathcal{R} & \text { Regionalised Design Rainfall } \\ S_{x}^{-} & \text {Slack variable } \\ S_{x}^{+} & \text {Remnant variable } \\ \text { VRS } & \text { Variable Returns to Scale } \\ \mathcal{Z} & \text { Rainfall depth } \\ \mu & \text { location parameter } \\ \alpha & \text { scale parameter } \\ \kappa & \text { shape parameter } \\ \theta & \text { Technical efficiency } \\ & \end{array}$

\section{Introduction}

58 An increasing number of communities flourishing near floodplains and their limited awareness and preparedness for flood events have contributed to an escalating loss of lives and property from floods (Shao et al., 2016; Ntajal et al., 2017; Mustafa el at., 2018). Hallegatte et al. (2013) reported an average global flood loss of US\$6 billion per year in 136 large coastal cities until 2005 , which is projected to increase to as high as US\$52 billion by 2050 through anticipated socioeconomic change alone. In a recent study, Alfieri et al. (2017) revealed that a $4^{\circ} \mathrm{C}$ increase in global temperatures would lead to a colossal increase in flood risk ( $>500 \%$ from the baseline 
period of 1976-2005) in countries representing nearly $73 \%$ of the world's population and $79 \%$ of the global GDP (Guhathakurta et al., 2011; Kadam \& Sen, 2012). Few studies have reported that Indian sub-continent has by far the highest share in terms of population and GDP exposed to river flood risk (Ward et al., 2013; Winsemius et al., 2013). Eastern India, comprising the states of Uttar Pradesh, Bihar, West Bengal, Assam, and Orissa, consistently experiences approximately $70 \%$ of the country's most severe flood impacts (Mohapatra \& Singh 2003). Under such disaster-looming conditions, detailed knowledge of risk through quantification of spatial and temporal characteristics of flood disasters is indispensable for designing any flood management programme under the umbrella of environmental planning and management.

Assessment of flood risk is a crucial topic of discussion that is to be treated with utmost gravity and commands global attention; it holds great importance to not only disaster management bodies but also the broader public (Dawson et al., 2011; Mugume et al., 2015; Muis et al., 2015; Shao et al., 2016). To date, a plethora of literature is available that address the assessment of flood risk by incorporating varied unique approaches. Few of such studies have followed a univariate approach by considering either flood depth (Sen \& Kahya, 2017) or population and land exposure (Usón et al., 2016; Moon et al., 2017; Arrighi et al., 2019) as proxies for flood risk. However, as correctly pointed out by Apel et al. (2009), the impacts of flooding are not limited to physical, economic and ecological damages alone but also include loss of lives and emotional trauma. It is thus a necessity to give equal consideration to this elephant in the room: socio-economic component.

The standard definition of flood risk $(\mathcal{R})$ consists of two major components, namely (i) flood hazard $(\mathcal{H})$ and (ii) vulnerability $(\mathcal{V})$, and is represented as a combination of both factors (Karmakar et al., 2010; Knighton et al., 2017). This concept has been implemented in several studies for evaluating flood risk in many flood-prone areas around the globe. In fact, the special 
report on Managing the risks of extreme events and disasters to advance climate change adaptation by the Intergovernmental Panel on Climate Change, identifies hazard and vulnerability as key drivers to flood risk. Flood hazard determines the probability of the occurrence of a flood at a specific location in space and time (Sarhadi et al., 2012; Domeneghetti et al., 2013). Here the degree of severity is mainly characterized in terms of (i) depth of floodwater $(d)$ and (ii) product of depth and velocity, as a proxy of momentum of flood water $(d \times f)$. Most of the studies have considered the former measure for flood hazard quantification, neglecting the impact of velocity, which is vital to understand human stability (Russo et al., 2013). Although several modeling approaches are used in practice for assessing flood hazard, hydrodynamic flood models (Thorndahl \& Willems 2007; Qiang et al., 2019) are widely accepted ones. These sophisticated models require multiple and extensive data sets, such as topographic (e.g., digital elevation model (DEM), built-up area, and man-made drainage network), hydrodynamic (e.g., river discharge and channel water level) and meteorological (e.g., rainfall) inputs. However, ensuring the availability of such data sets is a daunting task, especially when dealing with data-scarce flood-prone region existing in several developing and under-developed countries. In such occasions, reliable and easy-to-use algorithms should be exercised to obtain the data sets and utilize in flood inundation models to identify areas at different degrees of hazard. The second important component, vulnerability, determines the susceptibility and degree to which various physical, social, ecological, and environmental conditions are affected (UNISDR 2009; Balica et al., 2012). Turner et al. (2003) recognized 'vulnerability' as a key aspect to understand the management of a coupled humanenvironment system addressed as a vital theme under global environmental change and sustainability science. They further signify on the intricacy involved in vulnerability assessment as it is driven not just by hazards, but also influenced by sensitivity and resilience of the system experiencing such hazards. Several past studies have relied on 'damage curve', 
for quantifying vulnerability to various tangible components (physical, economic and ecological) and thus determine the overall risk factor (Bouwer et al., 2010; Arrighi et al., 2018). However, they overlooked the highly sensitive and complex: direct and indirect intangible side of vulnerability (socio-economic dimension). Unlike the tangible components, intangible ones are hard to quantify due to the irreversibility and complexity of the processes involved in understanding them (Halsnæs \& Kaspersen, 2014; Hammond et al., 2015; Olesen et al., 2015). Meyer et al. (2009) proposed a framework for integrated flood risk assessment by evaluating the expected annual average damage from flooding to economic, social, and environmental dimensions. In this work, the risk to population was quantified through a simple mesoscale approach, where the population density map was intersected with the inundation data and divided into various land-use categories to calculate damage. Kubal et al. (2009) and Scheuer et al. (2011) implemented a similar framework but by considering a few more indicators under different dimensions. On many occasions, the conventional damage curves are sensitive in quantifying accurate flood damages as they consider several assumptions (e.g., spatial and of relevant flood-related data and limitations in understanding the flood damage mechanisms (Merz et al., 2010). As a result of which, despite the damage curve idea having held sway over for long, its accuracy has been criticized on a number of occasions, as they are not customized to quantify the direct and indirect intangible socio-economic vulnerability. Another widely used idea - an indicator based approach-has been seen to be preferred in many recent floodrisk studies. Here various indicators are identified in the context of socioeconomic standards along with infrastructural, environmental, ecological, and other factors. The vulnerability is modeled through numerous robust multi-criteria techniques such as analytical hierarchy process (AHP) (Cozannet et al., 2013; Lyu et al., 2018), technique for 
order of preference by similarity to ideal solution (TOPSIS) (Zagonari \& Rossi, 2013; Lee et al., 2014) and data envelopment analysis (DEA) (Li et al., 2013; Sherly et al., 2015) etc. The adoption of the DEA technique in vulnerability assessment of disasters is a relatively newer idea. DEA uses a data-oriented approach for evaluating the performance of a set of peer entities called decision-making units (DMUs), which converts multiple inputs into multiple outputs (Charnes et al., 1978; Huang et al., 2012). Till now, very limited studies have adopted DEA to study flood vulnerability processes, which is why it requires more attention considering the robustness of the model. Socioeconomic vulnerability, an intangible component, is generally a much-discussed topic but then again it has rarely been addressed in depth in flood management quantitative nature of flood damage in terms of hazard.

The impacts of floods are not confined to just its technicalities; it is in our best interest to understand 'who' and 'to what degree' flooding may affect in a multifaceted society. At the same time, it is necessary to consider various groups and their dynamic heterogeneity existing in the population, as they may have different degrees of responses to floods. The present study attempts to bridge gaps between quantitative (hazard) and qualitative (vulnerability) understanding of risk by adopting a holistic and multivariate approach with a sociotechnocratic perspective. At the same time, it identifies the numerous difficulties in outreach associated with a comprehensive flood risk methodology in a typical data-scarce \& flood-prone 
region. The unified framework is demonstrated over Jagatsinghpur district in Odisha (India), one of the severely flood prone regions in India. The study starts with addressing issues underlying data scarcity and flood hazard quantification by utilizing design rainfall, design discharge, and design storm tide. An extensive set of socioeconomic indicators is incorporated at a very fine administrative scale into the robust DEA technique to identify areas with various degrees of vulnerability. A set of flood risk maps is generated for two temporal scenarios (Scenario-I: 1970-2011 and Scenario-II: 1970-2001) using the unique concept of a Riskclassifier in choropleth, which has never been addressed before in previous studies. The choropleth aims to aid in better visualization of the contribution of hazard and vulnerability towards risk, thus assisting in panning out appropriate flood management options. The proposed framework is generic and can benefit developing and under-developed countries that are particularly where data scarcity hinders the devising of appropriate flood management measures through risk.

\section{Materials and methods}

Jagatsinghpur (geographical area $\sim 1760$ sq. $\mathrm{km}$ and locations: $19^{\circ} 58^{\prime} \mathrm{N}$ to $20^{\circ} 23^{\prime} \mathrm{N}$ latitude and $86^{\circ} 3^{\prime} \mathrm{E}$ to $86^{\circ} 45^{\prime} \mathrm{E}$ longitude), is a semi-urban district located in the downstream stretches of the highly flood-prone Mahanadi river basin in the state of Odisha (formerly known as Orissa) India (Fig. 1). It comprises of 8 blocks, two municipalities, 8 tehsils (sub-district level) and 1320 villages, and has been regarded as a severely flood-prone area (Ray, 2006; RodriguezLlanes et al., 2016). It has been facing the wrath of severe floods almost annually with major ones having struck in 1955, 1969, 1980, 1982, 1994, 1999, 2001, 2003, 2006, 2008, 2011, and 2014 (District Emergency Operation Center, 2016).

The main causative factors contributing to elevated flood risk in the study area are attributed to its geographical location and demographic characteristics. Almost similar to the shape of a 
trigon, River Mahanadi and River Devi flow on two sides while the Bay of Bengal covers the other side. During Indian monsoon season (June to September), immense river flow (Patro et al., 2009; Samantaray et al., 2015) and tidal disturbances (Sahoo \& Bhaskaran, 2018) along the coastline (length $\sim 60 \mathrm{~km}$ ) contribute to flooding. The relative flatness of the terrain further leads to a prolonged receding time of floodwater, thus intensifying the overall risk factor. On the other hand, considering the demographic characteristics, the district is predominantly agrarian. The rural villages are at higher risk than the other few township and uninhabited areas. The twin reasons for the same being: (i) the majority of population depends on agriculture and allied activities such as paddy and wheat mills for their main source of income - which are highly vulnerable to flood damage (ii) despite facing numerous difficulties, the rural population refuse shifting to other places and stick to ancestral property (place attachment) for their livelihood (Mishra et al., 2010). The data used for detailed mapping and estimating flood risk is rather intensive and of four major types: (i) topographic, (ii) hydrodynamic, (iii) meteorological and (iv) demographic. A complete list of data sets, the purpose of use, and sources are provided in the supplementary table S1.

The present study addresses four key aspects in the path of quantifying flood risk, which is illustrated in Fig. 2. This unified framework includes (I) estimation of regionalized design rainfall $(\mathcal{R D} \mathcal{R})$ in a data-scarce situation (II) flood hazard mapping through hydrodynamic modeling (III) socio-economic vulnerability analysis and (IV) quantification of bivariate flood risk through Risk-classifier. 


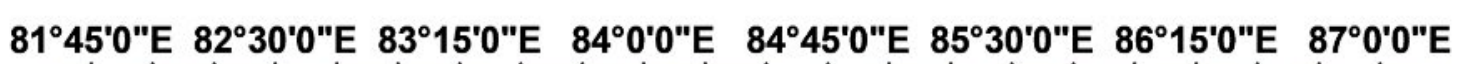
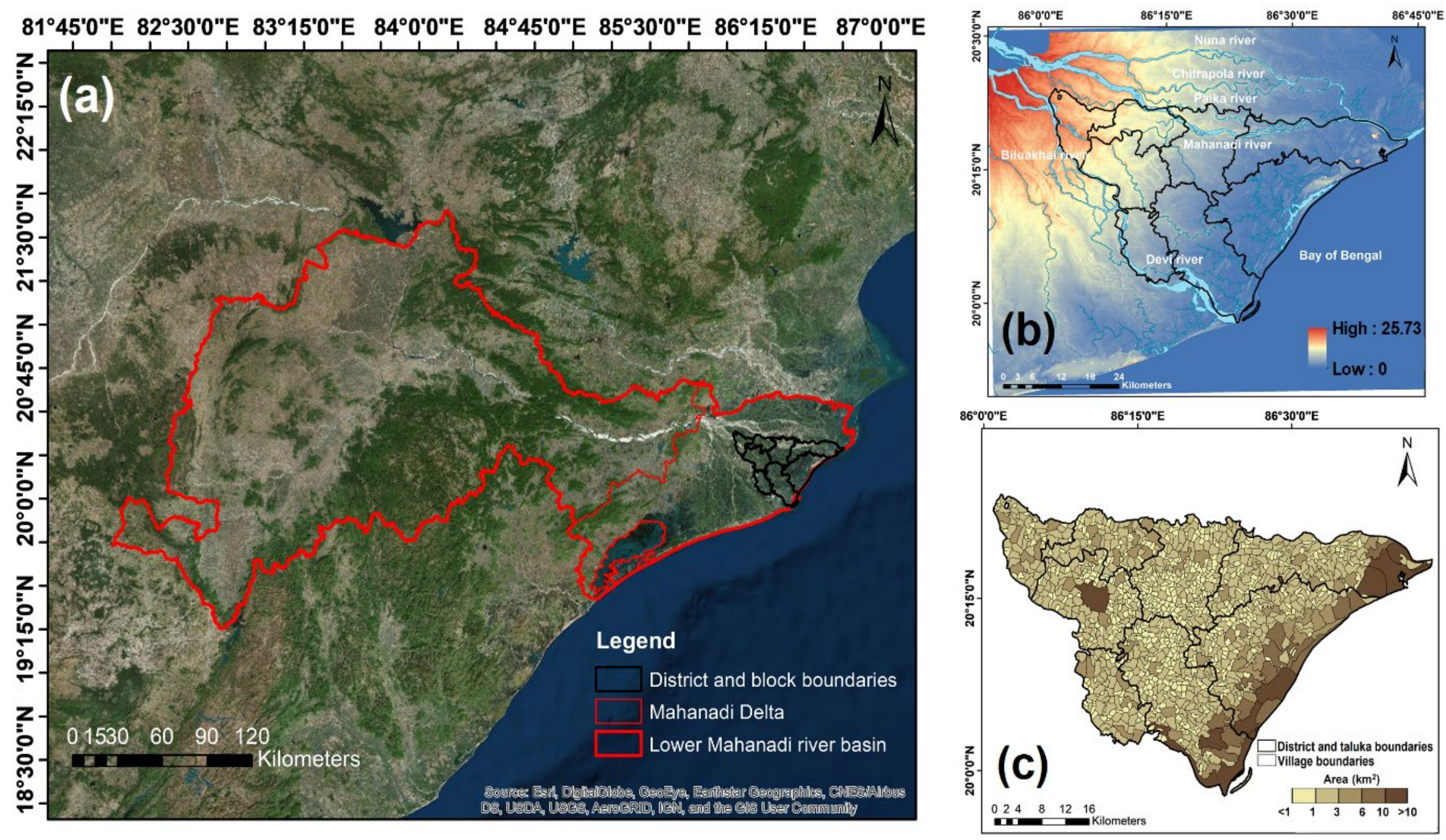

Fig. 1. Description of Jagatsinghpur district, Odisha (India): (a) Location of Jagatsinghpur district in the Lower Mahanadi river basin and delta region. (b) Description of bathymetry with river network details. (c) Various administrative blocks and village boundaries. 


\subsection{Estimation of $\mathcal{R D} \mathcal{R}$ in a data-scarce situation}

212 The availability of long term rainfall data is a prerequisite for any hydrological or

213 hydrodynamic model (Sharma et al., 2012; Worqlul et al., 2017). To overcome the situation of 214 data scarcity (mainly affected by discontinuity and inconsistency), various approaches such as station averaging (Buishand, 1991), regional averaging (Overeem et al., 2009), maximization of a joint likelihood function, spatial interpolation (Garcia et al., 2008; Wang et al., 2017) have been utilised in the past. Although these methodologies have their advantages and limitations, it is necessary to strive for a conservative approach which can retain the essential features of rainfall depth, duration and temporal pattern to describe its flood causing potential. In our study, a novel optimisation based regionalisation approach adopted by Mohanty et al. (2018) was implemented. Herein, long term rainfall data from rain-gauge stations lying outside the study area is utilized to derive $\mathcal{R \mathcal { R }} \mathcal{R}$ time series. The hourly rainfall data (1970-2011) for the three IMD operated stations located at Paradeep (coordinates: $20.3166^{\circ} \mathrm{N}, 86.6114^{\circ} \mathrm{E}$ ), Bhubaneswar (coordinates: $20.2961^{\circ} \mathrm{N} ; 85.8245^{\circ}$

E) and Puri (coordinates: $19.8134^{\circ} \mathrm{N}$; $85.8315^{\circ} \mathrm{E}$ ) were obtained. The complete duration was divided into two temporal parts i.e., 1970-2011 as Scenario-I and 1970-2001 as Scenario-II, to generate individual representative $\mathcal{R D} \mathcal{R}$ time series.

To depict the association between rainfall depth and duration, the rainfall events for each scenario were delineated to generate individual event series. A comprehensive marginal depth and duration frequency analysis were performed using General Pareto distribution (GPD) and various parametric and non-parametric distributions, respectively. In order to derive the joint probability using the two marginals of rainfall depth $(Z)$ and duration $(D)$, a bivariate frequency analysis was performed through copulas. Although there are different families of copulas, 
taking the upper tail dependence into consideration, we selected an extreme value type copula: Gumbel-Hougaard (G-H) copula.

Its distribution function is given by equation (1)

$$
C\left(r_{1}, r_{2}\right)=\exp \left\{-\left[\left(-\ln r_{1}\right)^{\omega}+\left(-\ln r_{2}\right)^{\omega}\right]^{1 / \omega}\right\}
$$

where $\omega \epsilon[1, \infty)$ determines the upper tail dependence; $r_{1}$ and $r_{2}$ are the cumulative probability distributions of rainfall depth and duration given by $\mathbf{F}_{\mathcal{Z}}(z)$ and $\mathbf{F}_{\mathcal{D}}(d)$ respectively.

The at-site Depth Duration Frequency (DDF) curves for the two scenarios were derived by considering the conditional probability of the copula for various pairs of return periods and durations. The conditional probability values yield the probability of the cumulative rainfall depth, the inverse of which yields the design rainfall depth that corresponds to a given return period and duration. The conditional probability is given by equation (2)

$$
\left.\left.C\left(r_{1} \mid r_{2}\right)=u_{2}^{-1} \times\left[\left(-\ln r_{1}\right)^{\omega-1}\right] \times\left(-\ln r_{2}\right)^{\omega}\right] \times\left(-\ln r_{2}\right)^{\omega}\right]^{(1 / \omega)-1}
$$

The design temporal pattern is identified as the unique pattern among all temporal patterns which demonstrated highest skew and kurtosis along with least bimodality. The at-site design rainfall depth value obtained for a given pair of design return period and design duration from the DDF curves were multiplied with the ordinates of the design temporal pattern to generate at-site design rainfall time series for each station. For regionalization of the at-site design rainfall, each parameter of the at-site DDF curve can be averaged to yield a single set of regionalized curves. However, this would be inappropriate if either or both of the marginal distributions follow a non-parametric model. To overcome this, we use an optimization based technique using two approaches, namely, (i) Complete Optimization (or CO) and (ii) Combined averaging optimization (or CAO). 

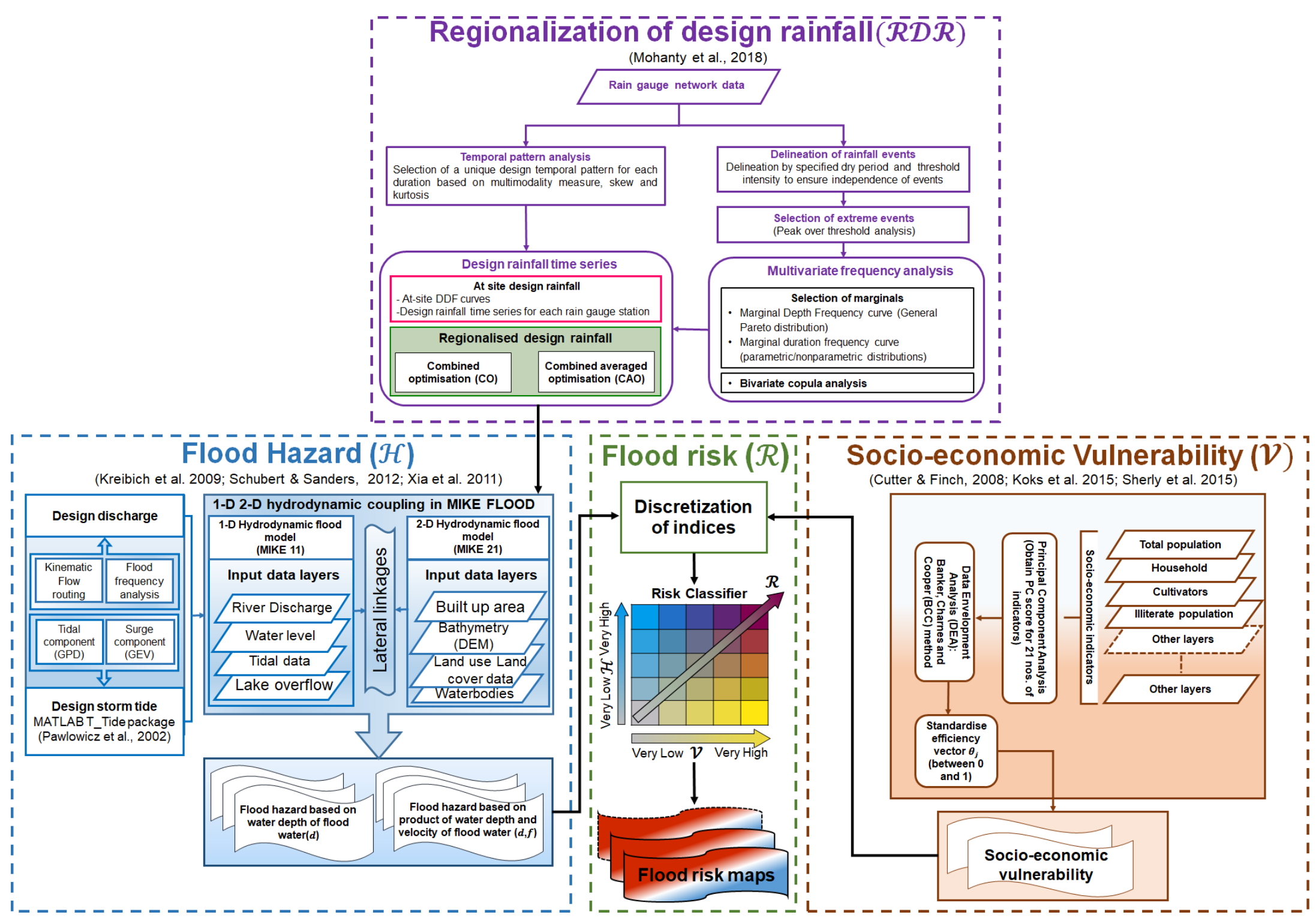

Fig. 2. A unified framework for flood risk mapping using the components of flood hazard and socio-economic vulnerability. 
In $\mathrm{CO}$, the optimization is performed considering the three GPD parameters ( $\mu$ : location

259

260

261

262

263

264

265

266

267

268

269

270

271

272

273

274

275

276

277

278

279 parameter, $\alpha$ : scale parameter, and $\kappa$ : shape parameter) and kernel bandwidth ( $h$ : nonparametric kernel bandwidth), thus obtaining four optimal values as outputs, while in CAO the three GPD parameters are averaged, while a non-linear optimization is used to derive the regional bandwidth for the kernel density function of marginal depth frequency. Here the objective function is to minimize root mean square error (RMSE) at the at-site stations resulting from the regional model. The optimization formulation is provided in equation (3). The regionalized copula parameter $(\omega)$ was obtained by proportionately weighting as per the record length in each station. The $\mathcal{R D} \mathcal{R}$ time series for both scenarios were obtained by combining the regionalized rainfall depth and design temporal pattern corresponding to a given return period and duration.

$$
\operatorname{Min} \mathcal{W}(x)=\sum_{i=1}^{N}(R M S E)_{i}, x=\left(x_{i} \mid i \in N\right)
$$

where $x_{i}=[\mu, \alpha, \kappa, h]_{i}$ and $x_{i}=[h]_{i}, \forall i \in N$ for complete optimization and complete averaged optimization respectively; $h$ is nonparametric kernel bandwidth; $\mu$ is the location parameter; $\alpha$ is the scale parameter and $\kappa$ is the shape parameter.

\subsection{Flood hazard mapping through hydrodynamic modeling}

Flood hazard is established through computational simulations of hydrodynamic models (Koks et al., 2015; Kourgialas \& Karatzas, 2017). To date, various 1D, 2D and/or 1D 2D coupled flood models are in practice which provides outputs primarily in the form of inundation extent, depth, and velocity of floodwater. However, these models are data-intensive and thus impede performance in data scarcity situations. Hence, there is a need to ascertain relevant algorithms to obtain the requisite inputs to a flood model. 


\subsubsection{Design discharge}

282 An essential component of a fluvial flood modelling framework is river channel discharge, which serves as the inflow boundary condition. The contribution of channel discharge is necessary to determine the volume of water overtopping the river banks, thus leading to inundation in the flood plains. Considering the unavailability of discharge information at the headwater location (Chainage ' 0 ' $\mathrm{m}$ ) on the main river channel in the $1 \mathrm{D}$ flood model domain, a kinematic routing procedure was adopted. Herein, the long term discharge (duration: 19702011) for a well-regulated gauge station at Tikarpara (location: $20^{\circ} 38^{\prime} \mathrm{N}$ and $84^{\circ} 37^{\prime} \mathrm{E}$ ), nearly $90 \mathrm{~km}$ upstream from the headwater flow point was obtained. The discharge was kinematically routed till the point of head water flow location for the channel residing in the study area. Since no major lateral inflows were present along this river channel network, the calculated discharge at the headwater flow point was not underestimated. Appropriate channel cross-sections and roughness were provided for this extent to determine the discharge at the downstream location. After obtaining the discharge at the boundary point, the widely used Generalized Extreme

Value (GEV) distribution (Morrison \& Smith, 2002; Ahilan et al., 2012) as given in equation (4), was used to obtain design discharge for various return periods.

$$
F(y ; \mu, \alpha, \kappa)=\left\{\begin{array}{l}
\exp \left[-\left(1+\kappa \frac{y-\mu}{\alpha}\right)^{-1 / \kappa}\right], \kappa \neq 0 \\
\exp \left[-\exp \left(-\frac{y-\mu}{\alpha}\right)^{-1 / \kappa}\right], \kappa=0
\end{array}\right.
$$

where $\mu$ is the location parameter; $\alpha$ is the scale parameter; and $\kappa$ is the shape parameter, respectively.

\subsubsection{Design storm tide}

An investigation of flooding due to the impact of tides and storm surge in coastal areas is necessary as they can lead to overtopping of defense mechanisms and inundation of low-lying areas, potentially leading to property damage and loss of life (Habel et al., 2017). The tide 
elevation at any given moment is a combination of various factors emerging from currents, changes in water density, meteorological factors, and hydrological effects from the proximity of rivers and estuaries (Quinn et al., 2014; Bilskie \& Hagen, 2018), and is given by equation (5) as shown below:

$$
\mathcal{H}(\mathrm{t})=\mathcal{H}_{0}(\mathrm{t})+\mathcal{H}_{\mathrm{s}}(\mathrm{t})+\mathcal{H}_{\mathrm{su}}(\mathrm{t})
$$

where $\mathcal{H}(\mathrm{t})$ is the observed water level or tide elevation at time ' $\mathrm{t}$ '; $\mathcal{H}_{0}(\mathrm{t})$ is the mean water level measured from the tide datum at time ' $\mathrm{t}$ '; $\mathcal{H}_{\mathrm{s}}(\mathrm{t})$ is the elevation of the astronomical tide at time ' $\mathrm{t}$ ' and $\mathcal{H}_{\text {su }}(\mathrm{t})$ is the elevation of surge at time ' $\mathrm{t}$ '.

The astronomical tide elevation $\mathcal{H}_{\mathrm{s}}(\mathrm{t})$ is the net result of multiple influences impacting tidal changes over certain periods of time. The primary constituents include Earth's rotation, the position of Moon and Sun relative to Earth, Moon's altitude (elevation) above Earth's equator, and bathymetry. The nature of the $\mathcal{H}$ distribution is defined by various tidal constituents (DiMarco \& Reid,1998), as expressed in equation (6).

$$
\mathcal{H}_{\mathrm{s}}(\mathrm{t})=\mathcal{H}_{0}+\mathcal{A}_{1} \cos (v \mathrm{t}+\mathscr{E}-\mathcal{g})_{1}+\mathcal{A}_{2} \cos (v \mathrm{t}+\mathscr{E}-g)_{1}+\ldots \mathcal{A}_{\mathrm{n}} \cos (v \mathrm{t}+\mathscr{E}-\mathcal{g})_{1}
$$

where $\mathcal{H}_{\mathrm{s}}(\mathrm{t})$ is the tide elevation at any time $\mathrm{t} ; \mathcal{H}_{0}$ is the height of the mean water level above a selected datum; $\mathcal{A}_{1,2, \ldots, \mathrm{n}}$ is the amplitude of the tide constituent; $v$ is the frequency (speed); $\mathscr{E}$ is the equilibrium argument of a constituent at $\mathrm{t}=0$ (from the astronomic event to $\mathrm{t}=0$ ); $g$ is the lag or epoch (from the astronomic event to the maximum amplitude of the constituent) and $n$ is the number of tide constituents.

The long-term (duration:1900 to 2100) astronomical tide elevation at Paradeep Station (location: $20.26^{\circ} \mathrm{N}, 86.70^{\circ} \mathrm{E}$ ) was used to determine the tidal constituents using MATLAB T_Tide package (Pawlowicz et al., 2002). Later, these constituents were utilized to generate a synthetic tide series for 2001 to 2011 . The difference between the synthetic and observed tide elevation provided the surge elevation. Thereafter, the astronomical tide elevation for various durations and return periods were obtained by using a GEV distribution (Hunter et al., 2017), 
while the surge component was determined by using GPD as provided in equation (7). The combined astronomical and surge elevation was used as the tide elevation into the 1-D model as the downstream boundary condition.

$$
F(y ; \mu, \alpha, \kappa)=\left\{\begin{array}{c}
1-\left[1-\kappa\left(\frac{y-\mu}{\alpha}\right)^{1 / \kappa}\right] \text { for } \kappa \neq 0 \\
1-\exp \left[-\left(\frac{y-\mu}{\alpha}\right)\right] \text { for } \kappa=0
\end{array}\right.
$$

where $\mu$ is the location parameter; $\alpha$ is the scale parameter and $\kappa$ is the shape parameter.

\subsubsection{D 2D coupled flood model set-up}

The flood hazard was quantified by using a commercially available MIKE FLOOD, which is a widely used hydrodynamic flood model (DHI 2013; Vojinovic \& Tutulic, 2009). It encompasses the 1D version in MIKE 11 for river channel modeling and the 2D version in MIKE 21 HD FM for overland or flood plain inundation modeling. Herein, the MIKE 11 model employs an implicit finite difference scheme developed by Abbott and Ionescu (1967) for solving the Saint-Venant equations, regardless of them being kinematic, diffusive, or dynamic. This robust scheme can support courant numbers as high as 10-20 if the flow is subcritical (with a Froude number less than 1). Additionally, the MIKE 21 HD FM model employs a nonorthogonal unstructured triangular mesh and is based on the numerical solution of the twodimensional incompressible Reynolds-averaged Navier-Stokes equations using the assumptions of Boussinesq and hydrostatic pressure (Warren and Bach, 1992; Papaioannou et al., 2016). A high-resolution LiDAR DEM (horizontal resolution: $2 \mathrm{~m} \times 2 \mathrm{~m}$ ) was utilized to represent the bathymetry for the entire study area. The preprocessing of the DEM (filling and breaching) was carried out in ArcGIS 10.5 to make it hydrologically conditioned for flood modeling. Later, the DEM raster file was imported to the MIKE domain through the grid to the MIKE toolbox. An unstructured mesh was generated for the entire study area in the MIKE 21 mesh generator. For more critical areas (along the river flood plains and coastal region, and 
built-up area), a finer mesh $\left(<100 \mathrm{~m}^{2}\right)$ was constructed. Rest of the domain was confined with a coarser mesh (1000-5000 $\left.\mathrm{m}^{2}\right)$. The DEM was imported into the mesh file and interpolated to define the final bathymetry domain for flood simulation. The flood plain roughness was generated by providing distributed Manning's resistance values for different land use classes as they may affect the flood pattern in the flood plains. The river channel flow using the design discharge and design storm tide was provided as boundary conditions in MIKE 11, while the $\mathcal{R D} \mathcal{R}$ for various return periods and durations was provided in MIKE $21 \mathrm{HD}$ FM for both the scenarios, respectively. The simulated outputs from MIKE 11 and MIKE 21 HD FM were coupled in the MIKE FLOOD model by providing lateral links between river cross-sections and the flood plains.

\subsubsection{Identification and discretization of flood hazard}

The degree of flood hazard is determined by the level of difficulties faced by human beings and/or damage to economic assets (Tingsanchali \& Karim, 2005). In most of the flood hazard studies carried out on urban and agricultural lands, $\mathcal{H}$ has been characterized conventionally by floodwater depth $(d)$. However, quantification with ' $d$ ' alone fails to account an important aspect: instability of humans during deep floodwater flows. To account for this, an improved criterion signifying momentum of floodwater which is given as the tuple of depth and incipient velocity ' $(d, f)$ ' is characterized (Kelman \& Spence, 2004; Aronica et al., 2012; Chen et al., 2018). So far, various ranges of ' $d$ ' and ' $(d, f)$ ' have been proposed. Generally, it is reported that ' $d$ ', as small as $0.2 \mathrm{~m}$, is within the self-help range for humans (adults), while beyond 1.5 $\mathrm{m}$ are hazardous to single-story buildings. Similarly, the critical range of ' $(d, f)$ ' lies between 0.6 to $2 \mathrm{~m}^{2} / \mathrm{s}$.

In this work, we identify $\mathcal{H}$ in terms of both ' $d$ ' and ' $(d, f)$ '. Since quantification of ' $d$ ' is straightforward, we explain the other criteria here. Let ' $\left(d_{k}, f_{k}\right)$ ' be associated momentum for 
every $k^{\text {th }}$ grid under consideration. The value of $\mathcal{H}$ depends on the tuple ' $\left(d_{k}, f_{k}\right)$ ' $\in \mathbb{C}^{2} \forall k \in$ $\mathbb{N}$, where $\mathbb{C}^{2}$ is the set of all such tuples, and hence hazard can be defined as a function in $\mathbb{C}^{2}$ as given in equation (8):

$$
\begin{gathered}
\phi: \mathbb{C}^{2} \rightarrow \mathcal{H} \in \mathbb{R}^{+} \text {such that } \\
h=\phi\left(\left(d_{1}, f_{1}\right), \ldots,\left(d_{k}, f_{k}\right)\right) ; h \in \mathcal{H} ; k \in \mathbb{N} \text { and }\left(d_{1}, f_{1}\right), \ldots,\left(d_{k}, f_{k}\right) \in \mathbb{C}^{2}
\end{gathered}
$$

where $\mathbb{R}^{+}$is the set of positive real numbers and $k$ is the total number of grids in the study area. In this study, five different classes are categorized from very low to very high, based on the values of function $\Phi\left(\left(d_{1}, f_{1}\right), \ldots,\left(d_{k}, f_{k}\right)\right)$ (Mani et al., 2014). The numerical depiction of this discretization is $1=$ very low, $2=$ low, $3=$ medium, $4=$ high, and $5=$ very high. This discretization is done by defining the mapping given in equations (9) and (10) in $\mathcal{H}$ :

$$
\Phi_{d}: \mathcal{H} \rightarrow \mathcal{H}_{\boldsymbol{d}} ; \mathcal{H}_{\boldsymbol{d}}=\left\{\boldsymbol{h}_{\boldsymbol{d}} \in \mathbb{N}: \boldsymbol{h}_{\boldsymbol{d}} \leq 5\right.
$$

$$
\boldsymbol{h}_{\boldsymbol{d}}=\left\{\begin{array}{l}
1,0 \leq \boldsymbol{h} \leq 0.3 \\
2,0.3<\boldsymbol{h} \leq 0.7 \\
3,0.7<\boldsymbol{h} \leq 1.2 \\
4,1.2<\boldsymbol{h} \leq 1.6 \\
5, \quad \boldsymbol{h}>1.6
\end{array}\right.
$$

where $\boldsymbol{h}$ and $\boldsymbol{h}_{\boldsymbol{d}}$ represent the value and index of flood hazard for $k^{\text {th }}$ grid.

Supplementary Table S2 provides the discretization of ' $d$ ' and ' $(d, f)$ ' into various $\mathcal{H}$ categories used in this study.

\subsubsection{Socioeconomic vulnerability analysis}

\subsubsection{Selection of indicators}

An array of 21 relevant socioeconomic indicators common in two temporal scenarios was selected (Supplemental table S3 and S4). These indicators were classified into positive (higher the quantity higher the vulnerability or cost-type) and non-positive (higher the amount lower the vulnerability or benefit type) categories based on their impacts during flood disasters as justified in the supplementary data. An initial standardization was conducted to reduce the 
401

402

403

404

405

406

407

408

409

410

411

412

multi-dimensionality in the indicators. Suppose I be the set of all such indicators, and $\mathbb{D M}$ be the set of DMUs (villages here). Let $a_{j n}$ be the score given to $j^{t h}$ DMU for $n^{t^{h}}$ indicator. Then the standardized value of indicators for $j^{t^{h}}$ DMU is given by equation (11):

$$
a_{j n}^{s t d}=\left\{\begin{array}{l}
\frac{a_{j n}-a_{j n}^{\min }}{a_{j n}^{m a x}-a_{j n}^{\min }}, \forall \mathrm{n} \in \mathbb{P} \mathbb{I} \subseteq \mathbb{I} \\
\frac{a_{j n}^{m a x}-a_{j n}}{a_{j n}^{m a x}-a_{j n}^{\min }}, \forall \mathrm{n} \in \mathbb{P} \mathbb{I}^{\mathrm{C}} \subseteq \mathbb{I}
\end{array}\right.
$$

where $\mathbb{P I} \subseteq \mathbb{I}$ is the set of positive indicators and $\mathbb{P I}^{C}$ complement set i.e., set of non-positive indicators.

\subsubsection{Principal components analysis}

In the next step, we perform principal components analysis (PCA) to decorrelate and reduce the dimensionality of the indicators. The principal components (PCs) depend solely on the covariance matrix. The covariance matrix of $\left[a_{j n}^{s t d}\right]^{J \times N}$ (where $J$ is the total number of DMUs/villages and $\mathbb{D M}=\{1,2, \ldots, . . J\})$ and $N$ is the total number of vulnerability indicators $\mathbb{I}$ $=\{1,2, . ., n, . ., N\}$ and $N>J$ will have order $N \times N$ i.e., square matrix. i.e. $\left[\hat{a}_{x n}^{s t d}\right]^{N \times N}$. There will be $N$ eigenvectors, if the characteristic equation of $\left[\hat{a}_{x n}^{s t d}\right]^{N \times N}$ has distinct roots (i.e., no repeated roots).

The $x^{\text {th }}$ principal component for $j^{\text {th }}$ DMU is given by equation (12):

$$
P C_{x j}=\sum_{n=1}^{N} \wp_{x n} * a_{j n}^{s t d} ;\left\|\wp_{x n}\right\|=1 \quad \forall x, j
$$

where $\wp_{x n}$ is the principal component score - the standardized positive or non-positive indicator under consideration.

\subsubsection{Data envelopment analysis (DEA)}

Data envelopment analysis (DEA) is a widely used nonparametric technique for estimating the relative efficiency of units, referred to as DMUs, when it is difficult to identify absolute measures of efficiency (Charnes et al., 1978; Saein \& Saen, 2012; Li et al., 2013; Mardani et 
al., 2017). The model optimizes each observation associated with a DMU with the objective of calculating a discrete piecewise frontier determined by the set of Pareto efficient DMUs. The efficiency of each DMU is then measured by the distance of its input-output vectors to a piecewise linear frontier. In this study, the slack-based input-oriented BCC method (named after Banker, Charnes, and Cooper) (Banker et al., 1984), which considers variable returns to scale (VRS) given by equations (13) to (16), was adopted:

$$
\min \left[\theta_{j}-\xi\left(\sum_{x=1}^{X} S_{x}^{-}+\sum_{x=1}^{X} S_{x}^{+}\right)\right]
$$

$$
\text { such that } \sum_{j=1}^{J} \lambda_{j} * P C_{x j}+\sum_{x=1}^{X} S_{x}^{-}=\theta_{j} * P C_{x j} ; \forall x=1, \ldots, X
$$

$$
\sum_{j=1}^{J} \lambda_{j} * Q C_{x j}-\sum_{x=1}^{X} S_{x}^{+}=Q C_{x j}, \forall x=1, \ldots, X
$$

$$
\sum_{j=1}^{J} \lambda_{j}=1 ; \lambda_{j}, \xi, S_{x}^{-}, S_{x}^{+} \geq 0 \quad \forall x, j
$$

The vulnerability for $j^{t h}$ village is given by $\mathcal{V}_{j}=1-\theta_{j}$

where $\theta(0<\theta<1)$ is the technical efficiency of the village; $\lambda_{j}$ is the weight assigned to $j^{\text {th }}$ village and $S_{x}^{-}$and $S_{x}^{+}$are the slack and remnant variables.

\subsubsection{Discretization of vulnerability indices}

Similar to hazard, we discretized the vulnerability indices into five different classes from very low to very high, based on the values of function $f\left(i_{1}, \ldots, i_{n}\right)$. This discretization is done by defining the mapping in $\mathcal{V}$ as given in equations (17) and (18):

$$
f_{d}: \mathcal{V} \rightarrow \mathcal{V}_{d} ; \mathcal{V}_{d}=\left\{v_{d} \in \mathbb{N}: v_{d} \leq 5\right.
$$

$$
v_{d}=\left\{\begin{array}{c}
1, \quad 0.1 \leq v \leq 0.2 \\
2, \quad 0.2<v \leq 0.3 \\
3, \quad 0.3<v \leq 0.4 \\
4, \quad 0.4<v \leq 0.5 \\
5, \quad v>0.5
\end{array}\right.
$$

where $v$ and $v_{\boldsymbol{d}}$ represent the value and index of vulnerability for $j^{\text {th }}$ village. 


\subsubsection{Quantification of bivariate flood risk through Risk-classifier}

441 Rather than considering the conventional univariate approach, we consider a new of its kind bivariate approach for quantifying flood risk. The innovative bivariate approach helps to identify different levels of flood risk $(\mathcal{R})$, with individual contributions coming from hazard and vulnerability $(\mathcal{V})$. The bivariate concept has been used in climate research by Speich et al. (2015) and Retchless \& Brewer (2016), owing to its detailed manifestation of two influencing components. We would like to highlight that the concept of bivariate representation of flood risk has not been used in any previous study. In our study, we used the information on flood hazard, and vulnerability derived earlier to identify flood risk. The aggregated contribution of $\mathcal{V}_{d}$ and $\mathcal{H}_{d}$ towards $\mathcal{R}$ is determined through transformation provided in equation (19):

$$
\text { such that } \mathcal{R}\left(v_{d}, h_{d}\right)=\left\{m_{p, q} \in \mathbf{M}^{p^{\times}} q_{: m_{p, q}}=\left(v_{d}, h_{d}\right)\right\} ; \forall v_{d} \in \mathcal{V}_{d} \text { and } h_{d} \in \mathcal{H}_{d}
$$

where $p$ and $q$ are the cardinality of $\mathcal{V}_{d}$ and $\mathcal{H}_{d}$, and $\circledast$ is the Cartesian product in $\mathcal{V}$ and $\mathcal{H}$.

The graphical depiction of matrix $\mathrm{M}^{p^{\times}} q$ is portrayed through a $5 \times 5$ choropleth as illustrated in the supplemental Fig. S1. Here the upper triangular cells bordered by pink color indicate $\mathcal{R}$ driven by $\mathcal{H}$, while the lower triangular cells bordered by green color indicate $\mathcal{R}$ driven by $\mathcal{V}$. The cells in the diagonal indicate an equal contribution of $\mathcal{H}$ and $\mathcal{V}$ to the overall $\mathcal{R}$.

\section{Results and discussions}

\subsection{Changes in decadal at-site and RDR}

A representative illustration of the at-site design rainfall and $\mathcal{R D} \mathcal{R}$ time-series is provided in supplemental Fig. S2. While considering at-site stations, Paradeep recorded a higher rainfall depth for all return periods and durations for both the scenarios, followed by Bhubaneswar and 
Puri received 657, 636 and $599 \mathrm{~mm}$ depth of rainfall, respectively. The $\mathcal{R D} \mathcal{R}$ depth is also found to be higher in Scenario-I than Scenario-II for all return periods and durations. For instance, for a 100-yr 24-h duration event, the rainfall depth was found to be $705 \mathrm{~mm}$ for Scenario-I, while it was $578 \mathrm{~mm}$ for Scenario-II. The increase in total depth of the rainfall was attributed to the extreme monsoonal rainfall events that occurred in the district in 2008 and 2011, which eventually led to flood events as well. Apart from monsoonal rainfall, the additional rainfall contribution in this station was a result of cyclonic depressions arising in the Bay of Bengal. According to Cyclone e-Atlas IMD (http://www.rmcchennaieatlas.tn.nic.in/), nine major rainfall events occurred between 2001 and 2011 due to depressions resulting in an increase in rainfall over the region.

\subsection{Flood inundation and hazard analysis}

The flood model simulations are estimated for different return periods $(50,100$, and 200-yr) and durations $(6,12$, and $24-\mathrm{h})$. This information is utilized to derive flood hazard (referred to as $\mathcal{H}$ in the results section) maps on the basis of both floodwater depth ' $d$ ' and the tuple of floodwater depth and velocity ' $(d, f)$ '. These maps are illustrated in Fig. 3 and Fig. 4 for a 100yr return period and 6,12 , and $24-\mathrm{h}$ duration event. The inset bar graphs depict the percentage of area falling under high $\left[d>1.5 \mathrm{~m}\right.$ or ' $(d, f)$ ' $\left.>1.2 \mathrm{~m}^{2} / \mathrm{s}\right]$ and very high $[d>3.5 \mathrm{~m}$ or ' $(d, f)$ '> $\left.1.6 \mathrm{~m}^{2} / \mathrm{s}\right] \mathcal{H}$ classes. The rest maps for 50 and $200-\mathrm{yr}$, and 6, 12, and 24-h durations are provided in the supplemental Figs. S3 to S6. A rise in flood depths and inundation extent is observed with longer durations in both the scenarios (Fig. 3; 4 (a), (b) and (c)). This observation is reflected in the $\mathcal{H}$ behavior as well in both the scenarios (Fig. 3; 4 (d) to (i)). In $\mathcal{H}$ maps represented in terms of depth $(d)$ and tuple of floodwater depth and velocity ' $(d, f)$ ', the regions experiencing high and very high flood $\mathcal{H}$ increase with longer durations. For instance, the percentage of area under high and very high flood depth in Scenario-I was $18.44 \%$ for a $6-\mathrm{h}$ event, which eventually increased to 19.32 and $20.63 \%$ for a 12 -h and 24 -h event, respectively. 
488 A similar observation is noticed in the other expression of $\mathcal{H}$ as well (16.68\% for 6-hr event,

489

490

491

492

493

494

495

496

497

498

499

500

501

502

503

504

505 $18.72 \%$ for 12 -hr event and $20.93 \%$ for 24 -h event). While comparing $\mathcal{H}$ quantified by $(d)$ and ' $(d, f)$ ', we notice a rise in areas falling under very high $\mathcal{H}$. This rise is due to the inclusion of velocity in the $\mathcal{H}$ expression, which is able to capture the momentum which is otherwise overlooked with $d$ alone. The high $\mathcal{H}$ regions in both scenarios are observed near the flood plains of the River Mahanadi and River Devi as well as in the coastal belt. The flood plains show high and very high $\mathcal{H}$ due to high river discharge from the Mahanadi River and Devi River (considered as $\mathrm{u} / \mathrm{s}$ boundary point in flood model), while the coastal region experienced notable flooding due to tide surge impacts. Herein, the most significant finding is the larger percentage of area under high and very high $\mathcal{H}$ in Scenario-I compared to Scenario-II. Figs. 5 and 6 depict the observations in $\mathcal{H}$ for both the scenarios when expressed in terms of both ' $d$ ' and tuple of ' $(d, f)$ '. We observed that the percentage of area under high $\mathcal{H}\left[{ }^{\prime}(d, f)\right.$ ' $\left.>1.2 \mathrm{~m} / \mathrm{s}^{2}\right]$ was higher while utilizing tuple of ' $(d, f)$ ' than ' $d$ ' alone. For example, in a 100-yr and 24-h event, the contribution of high $\mathcal{H}$ considering ' $(d, f)$ ' was $20.93 \%$ and $18.07 \%$ (Fig. 5), and considering ' $d$ ' (>1.5 m) was $20.63 \%$ and $18.57 \%$ (Fig. 6), respectively. Similar observations were noticed with other return periods and durations as well. Further to quantify $\mathcal{H}$ into different classes, we utilize the information derived from tuple of ' $(d, f)$ ', as it is a more conservative and better scientific approach than identified by ' $d$ ' alone. 

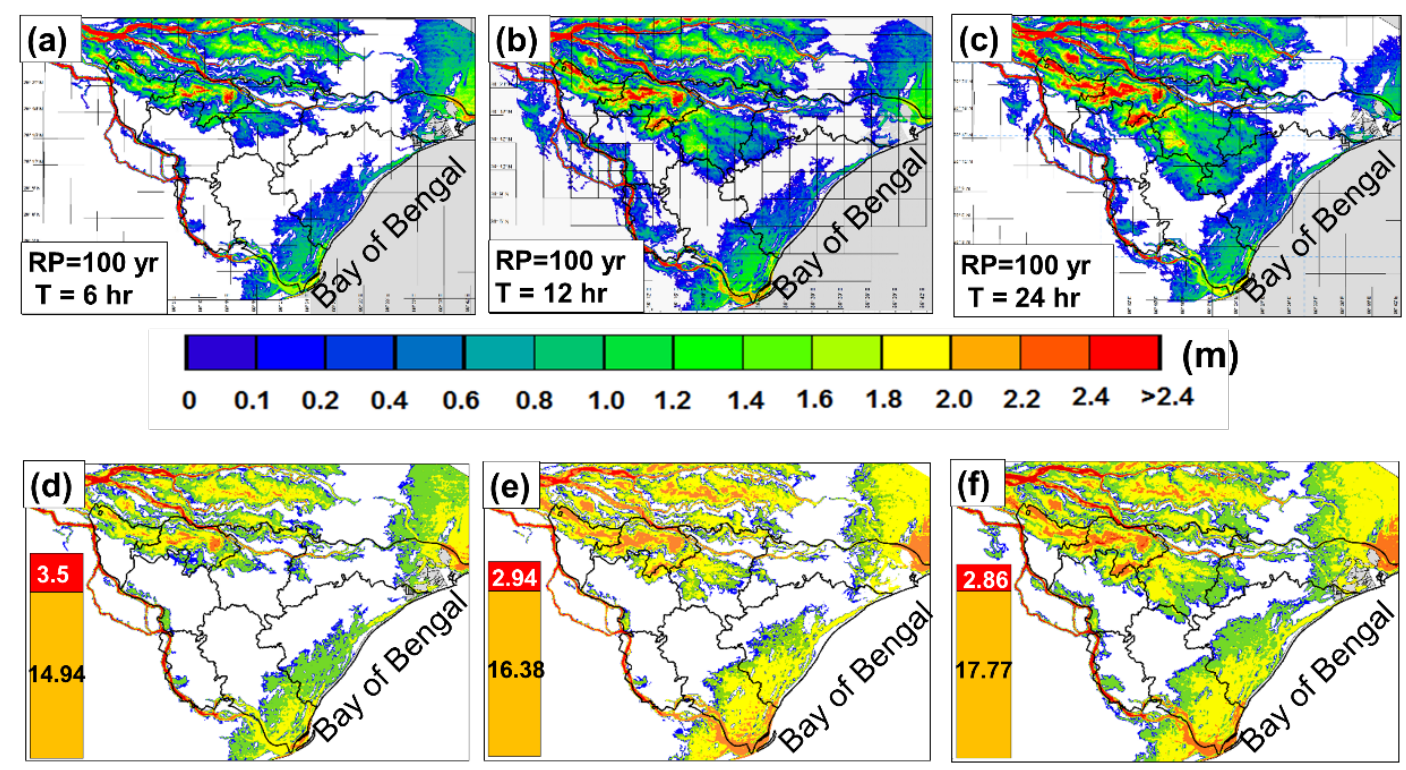

\begin{tabular}{|l|l|l|l|l|l}
\hline Very Low & Low & Moderate & High & Very high & $(\mathrm{m})$
\end{tabular}

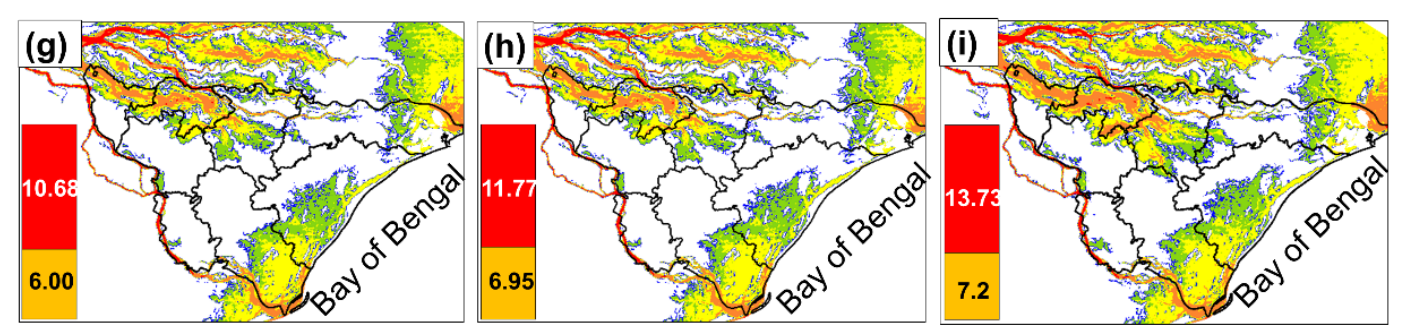

\begin{tabular}{|l|l|l|l|l}
\hline Very Low & Low & Moderate & High & Very high \\
$\left(\mathrm{m}^{2} / \mathrm{s}\right)$
\end{tabular}

507 Fig. 3. Flood simulation outputs (a, b, and c) derived with 1D-2D coupled MIKE FLOOD model and hazard $(\mathcal{H})$ maps computed using depth $(d)$ $508(\mathrm{~d}, \mathrm{e}$, and $\mathrm{f})$ and tuple of depth and velocity ' $(d, f)^{\prime}(\mathrm{g}, \mathrm{h}$, and i) for Jagatsinghpur district (Odisha, India) for return period of 100-yr and duration of 6, 12, and 24-hr for Scenario-I. 

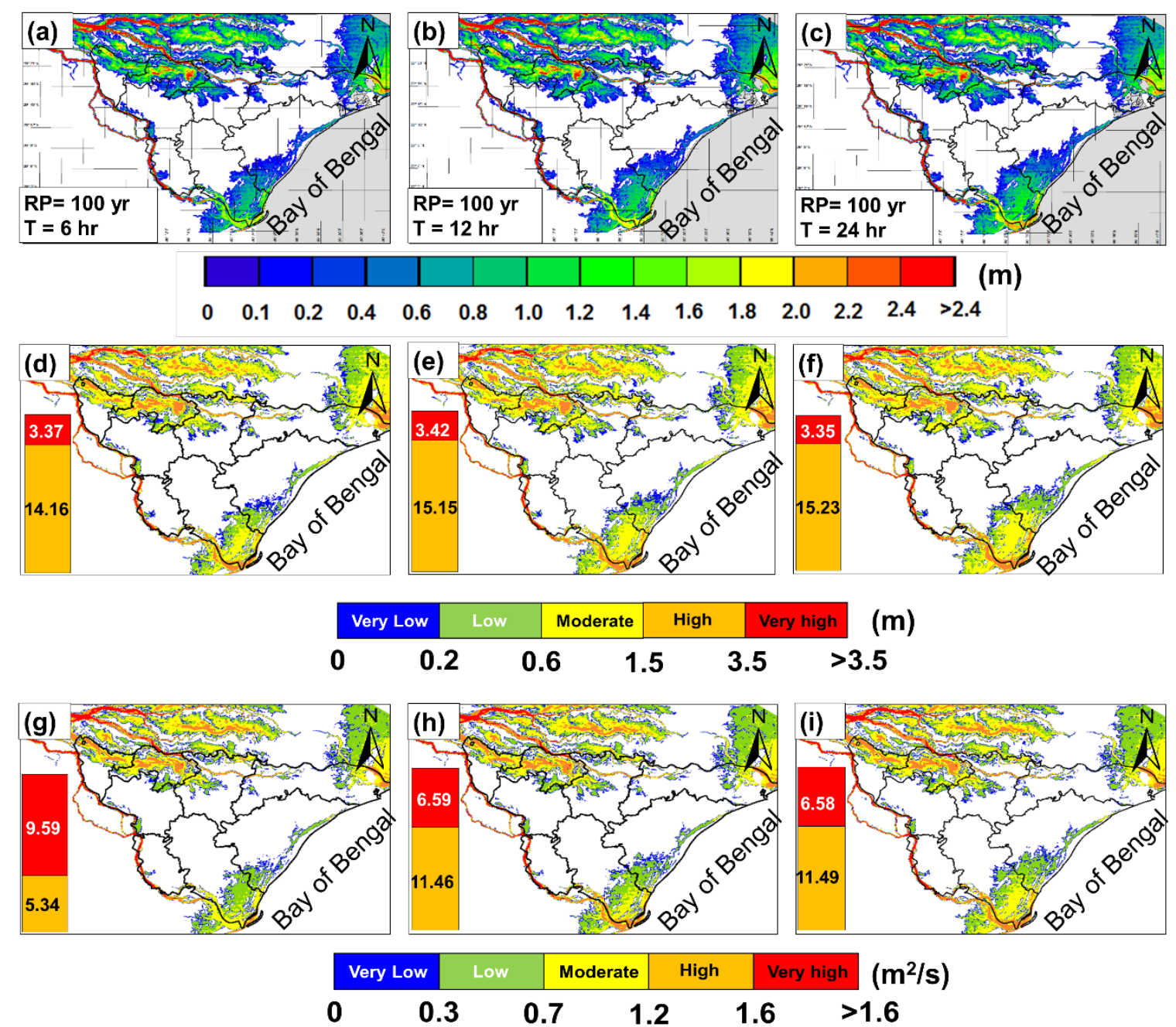

Fig. 4. Flood simulation outputs (a, b, and c) derived with 1D-2D coupled MIKE FLOOD model and hazard $(\mathcal{H})$ maps computed using depth $(d)$ $(\mathrm{d}, \mathrm{e}$, and $\mathrm{f})$ and tuple of depth and velocity ' $(d, f)^{\prime}$ ( $\mathrm{g}$, h, and i) for Jagatsinghpur district (Odisha, India) for return period of 100-yr and duration of 6, 12, and 24-hr for Scenario-II. 


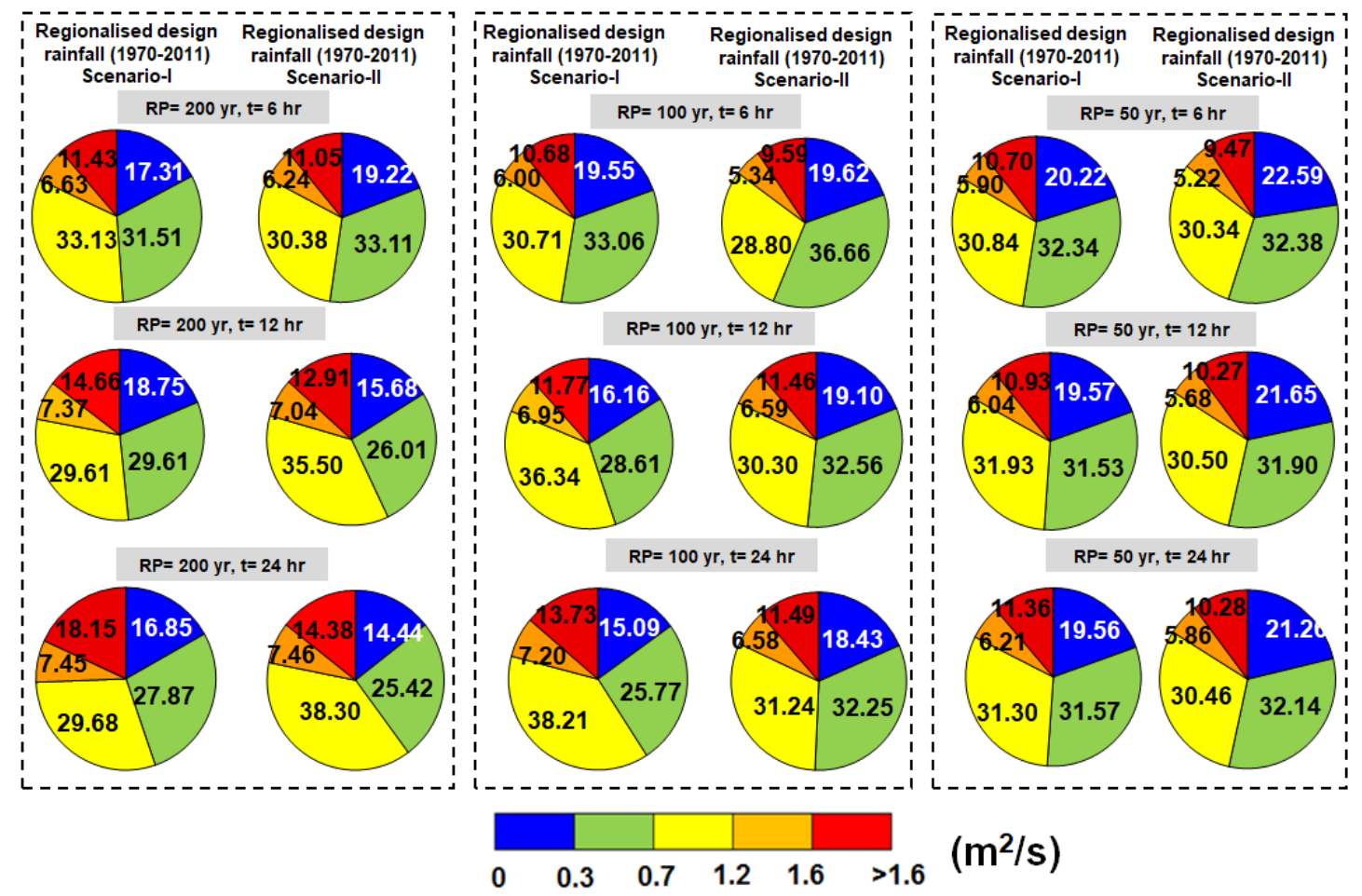

515 Fig. 5. Comparison of percentage distribution of hazard $(\mathcal{H})$ derived as a tuple of depth and 516 velocity ' $(d, f)$ ' for Scenario-I and Scenario-II in Jagatsinghpur district (Odisha, India).

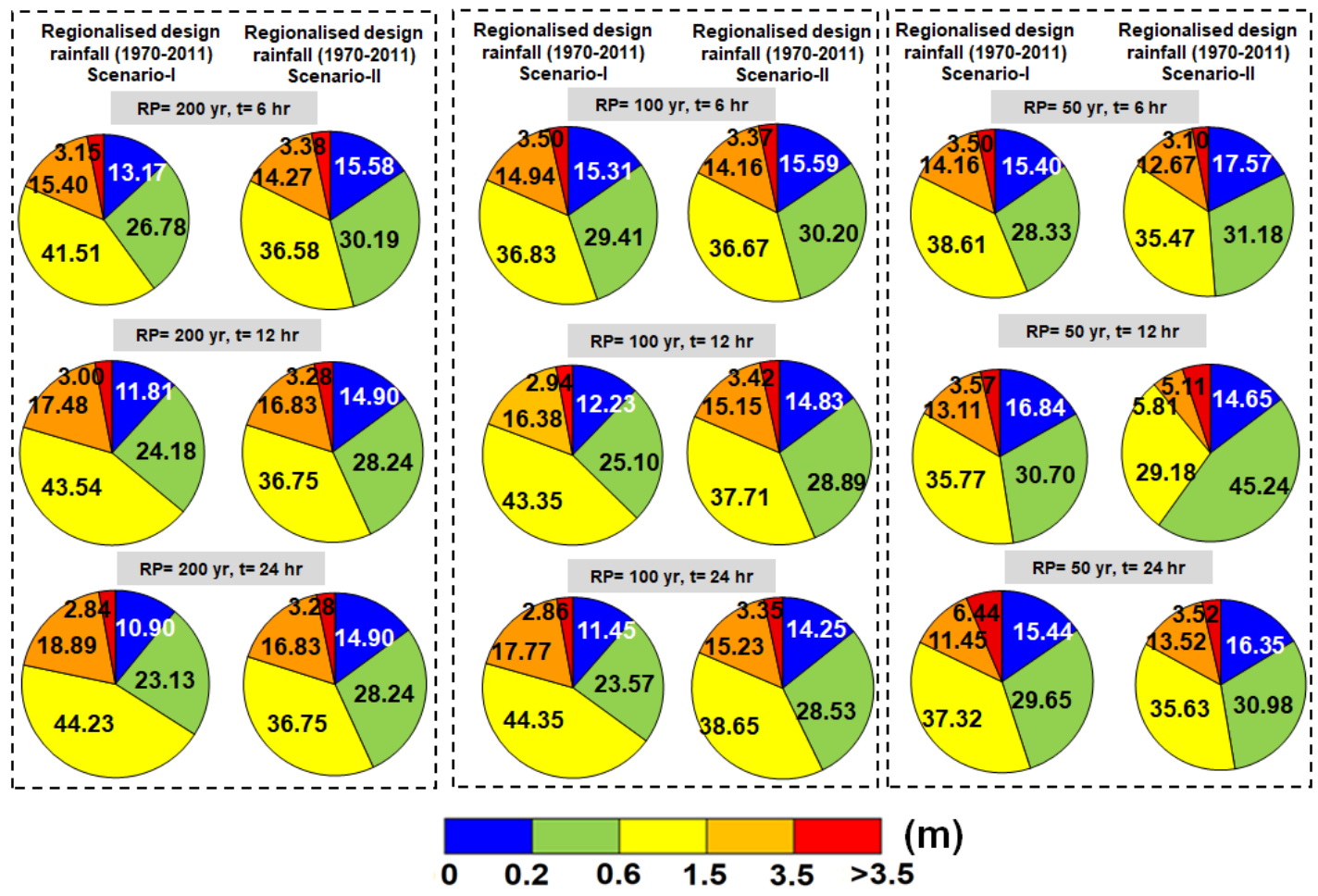

518 Fig. 6. Comparison of percentage distribution of hazard $(\mathcal{H})$ based on depth ' $d$ ' for Scenario-I 519 and Scenario-II in Jagatsinghpur district (Odisha, India). 
520 The $\mathcal{H}$ values were categorized into five different classes into very low, low, medium, high

521 and, very high, to determine the severity in a particular region. The $\mathcal{H}$ maps for both the

522 scenarios and the difference between them are provided in Fig.7 (a), (b), and (c)). A prominent

523 increase in the very high $\mathcal{H}$ regions is seen in Scenario-I, along the coastline covering the

524 Ersama and Balikuda blocks and lower stretches of the Mahanadi river covering the

525 Raghunathpur, Tirtol and Jagatsinghpur blocks. This change is clearly observed in the change

526 plot as well.
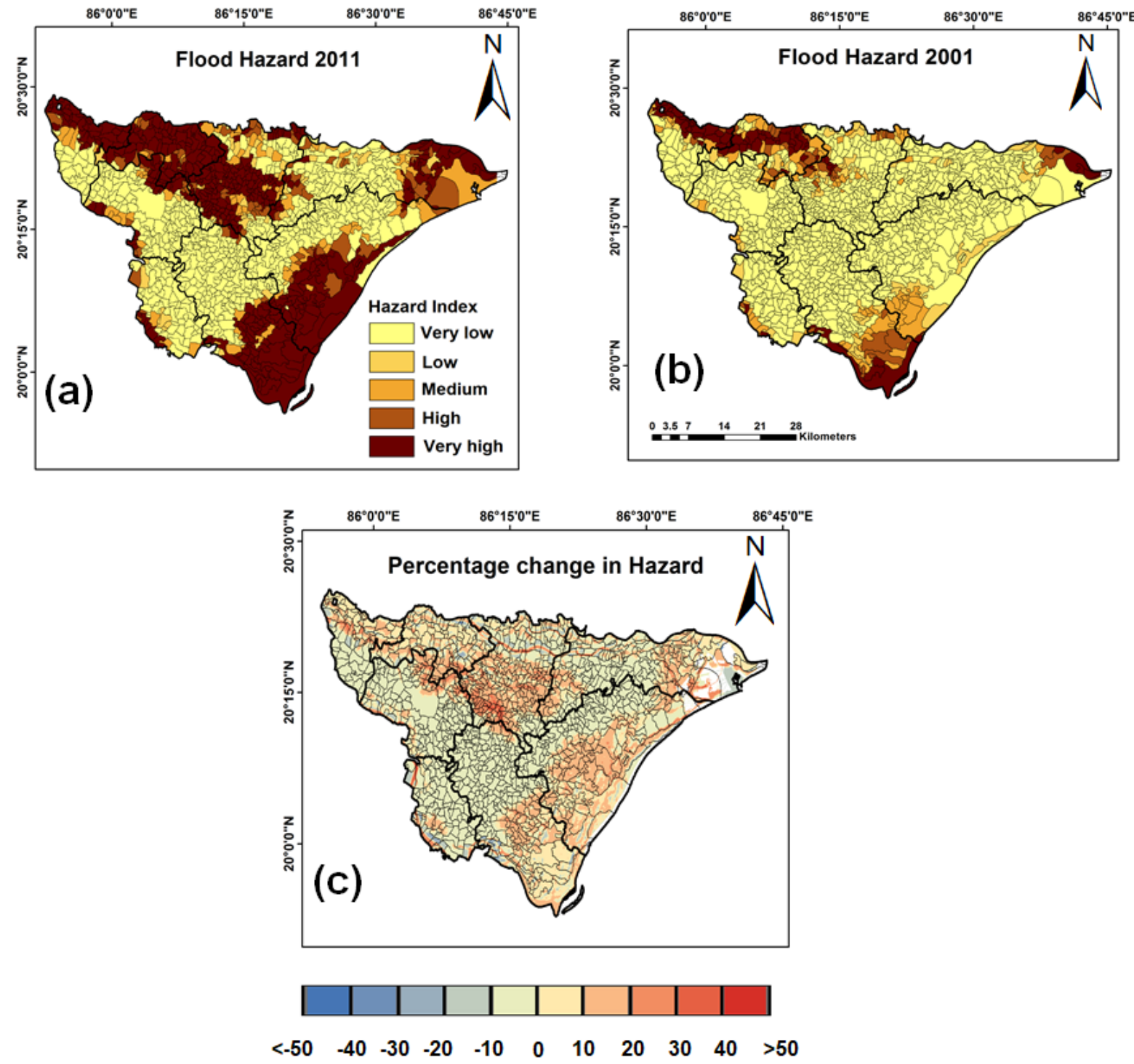

528 Fig. 7. Hazard $(\mathcal{H})$ maps for a 100-yr return period and 24-hr event for (a) Scenario-I (b) 529 Scenario-II and (c) percentage change over the scenarios for Jagatsinghpur district (Odisha, 530 India). 


\subsection{Changes in decadal socioeconomic vulnerability}

532 The percentage contribution of various indicators towards socio-economic vulnerability 533 (referred to as $\mathcal{V}$ in the results section) for both the scenarios is provided in Fig. S7 534 (supplementary material). The red dotted line represents the threshold above which the indicators show a significant percentage contribution towards $\mathcal{V}$. Although all the indicators contributed nearly equally, most of the non-positive indicators were predominant in their contribution to the overall $\mathcal{V}$. Interestingly, the number of households (positive indicator) determines the highest percentage contribution to $\mathcal{V}$ in Scenario-I, while in Scenario-II total population (positive indicator) determines the highest percentage of contribution. The impact of indicators pertaining to water resources such as (i) the status of hand-pumps, (ii) wells, (iii) river, (iv) tanks, and (v) power supply shows less influence on the $\mathcal{V}$. From these observations, we realize that the relationship between the $\mathcal{V}$ values contributed by different indicators is a complex phenomenon. A percentage change plot of these indicators was created to understand the contribution to overall $\mathcal{V}$. The results are provided in Fig. S8 (supplementary data). The inset pie charts represent the positive changes and non-positive changes over the decadal time scales. We observe a positive increase with most of the indicators. Among the positive

547 indicators, most of which contributed significantly to $\mathcal{V}$, the number of households, female population, total population, SC and ST population, SC and ST female population, and others showed positive changes. However, a few others, such as illiterate female population, illiterate population, and the population of children and marginal workers showed non-positive changes.

551 Similarly, to $\mathcal{H}$, the $\mathcal{V}$ was classified in categories from very low to very high. The $\mathcal{V}$ maps for the two-time scales and their difference is illustrated in Fig. 8. The $\mathcal{V}$ in Scenario-I was identified using a large number of medium and highly vulnerable areas. There were few villages facing very high $\mathcal{V}$, but over the next decade, an increase in the number of villages 
facing high $\mathcal{V}$ was noticed. Interestingly, many more villages were also seen to face higher $\mathcal{V}$ than in the previous decade. The conversion of villages facing different degrees of $\mathcal{V}$ is

557 prominent in the change plot. The overall $\mathcal{V}$ is seen to reduce over the time scale, as a slightly

558 higher percentage of villages showing non-positive $\mathcal{V}$ change was observed. We tried to 559 identify a few villages that faced a severe diametric change in $\mathcal{V}$ from very low (in Scenario-II or 2001) to very high (in Scenario-I or 2011). These villages are identified by cyan borders in Fig. S9 (supplementary data. The increase in $\mathcal{V}$ in these regions is due to rise in the number of positive indicators such as the number of households, SC and ST population, SC and ST female population and marginal workers, which were earlier seen to have a profound influence on $\mathcal{V}$.

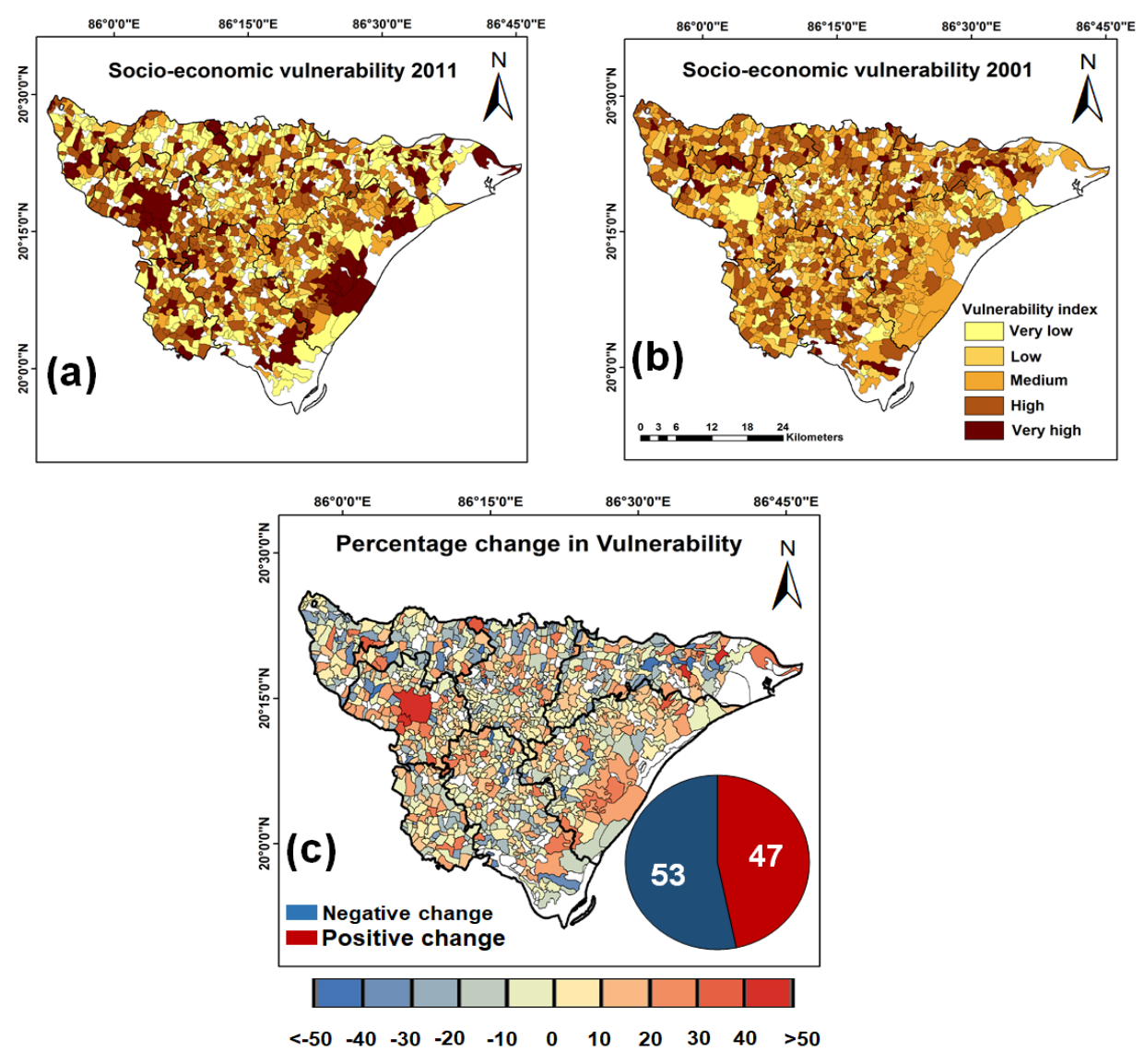
565 Fig. 8. Socio-economic Vulnerability (V) maps for (a) Scenario-I, (b) Scenario-II, and (c) percentage change over the scenarios for Jagatsinghpur district (Odisha, India).

567 A sensitivity analysis was conducted to test the significance of the three most significant positive (number of households, SC \& ST population, and SC \& ST female population) and 
non-positive indicators (literate population, working population, and female literate population) on $\mathcal{V}$. The changes in vulnerability is provided in the Fig. S10 (supplementary data). As expected, the removal of positive indicators leads to a decrease in $\mathcal{V}$ and vice versa. The removal of non-positive indicators leads to an increase (59\%) as compared to a decrease $(41 \%)$ in $\mathcal{V}$, whereas the removal of positive indicators leads to a decrease (54\%) compared to an increase $(46 \%)$ in $\mathcal{V}$.

\subsection{Estimation and mapping of decadal flood risk}

A new concept of bivariate flood risk $(\mathcal{R})$ through Risk-classifier representing different degrees of $\mathcal{H}$ and $\mathcal{V}$ was introduced. The bivariate representation discerns the respective contribution of risk from $\mathcal{H}$ and/or $\mathcal{V}$, thus identifying whether the risk is predominantly dominated by $\mathcal{H}$ or $\mathcal{V}$. Fig. 9 illustrates the $\mathcal{R}$ maps for Jagatsinghpur District, represented using a unique $5 \times 5$ choropleth for both scenarios. The values in the inset bivariate choropleth indicate the percentage of villages having a certain degree of $\mathcal{R}$ for a given scenario. A contrasting nature of risk was noticed in both the decades. While Scenario-I was identified predominantly by $\mathcal{H}$ and $\mathcal{H} \& \mathcal{V}$-driven risk, most villages in Scenario-II faced $\mathcal{V}$-driven risk. We also observe a substantial increase in high and very high risk due to both $\mathcal{H}$ and $\mathcal{V}$ in Scenario-I. These villages facing very high risk due to $\mathcal{H}$ alone or both $\mathcal{H}$ and $\mathcal{V}$ were located in the $\mathrm{N}-\mathrm{W}$ Jagatsinghpur District, including the lower reaches of the Mahanadi River (Biridi, Raghunathpur, and Tirtol blocks) and the S-E Jagatsinghpur District including the coastal region (Ersama block). The other villages in the Jagatsinghpur, Balikuda, and Nuagaon blocks faced risk due to high $\mathcal{V}$ but low $\mathcal{H}$. In the other scenario, risk was contributed largely from $\mathcal{V}$ and less significantly from $\mathcal{H}$. Few other villages located in the N-W and S-E Jagatsinghpur district faced lower risk with equal contribution from $\mathcal{H}$ and $\mathcal{V}$. However, the degree of risk intensified in these villages in the later time period, thus placing them in high and very high flood risk zones. 

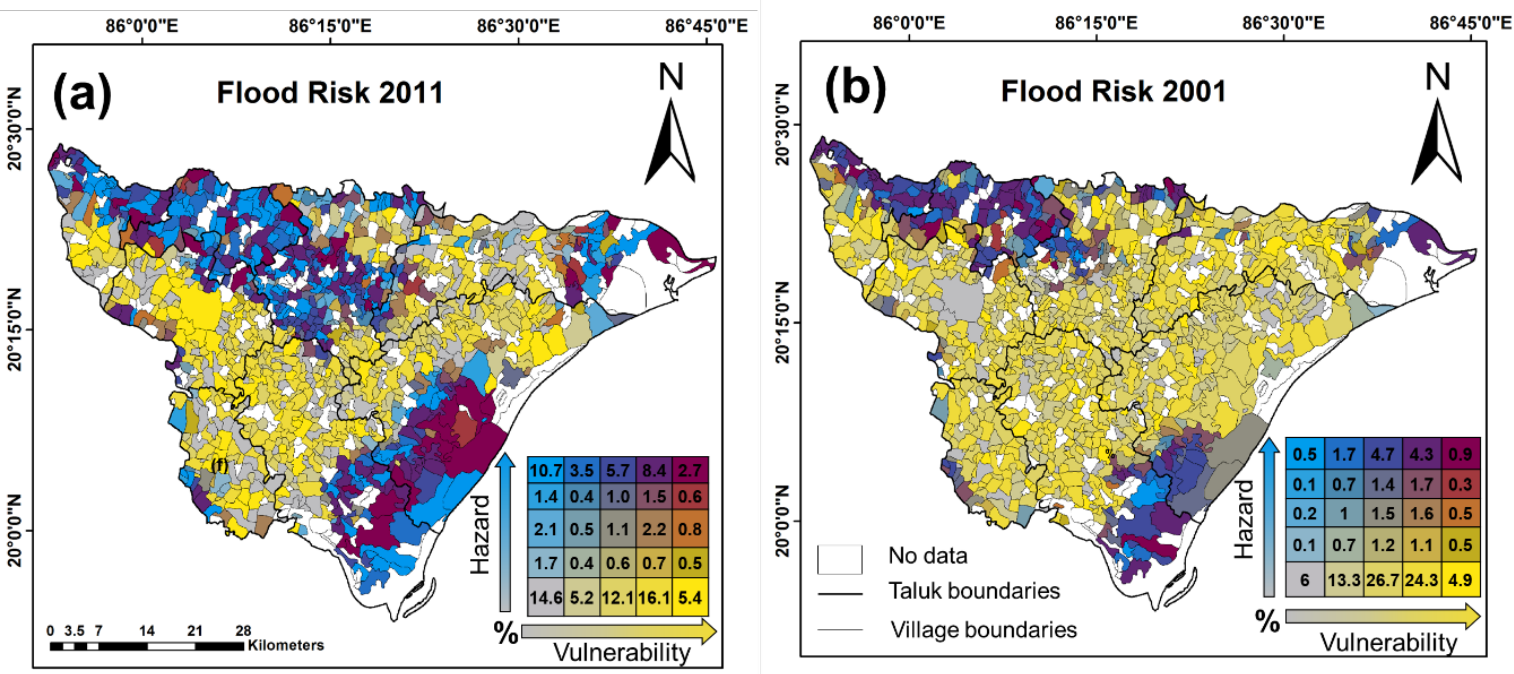

594

595

596

597

598

599

600

601

602

603

604

605

606

607

608

609

610

Fig. 9. Risk ( $\mathcal{R})$ maps for (a) Scenario-I and (b) Scenario-II. The values in the inset choropleth indicate the percentage of villages having a certain degree of $\mathcal{R}$ for a given scenario.

\section{Conclusions}

The estimation and mapping of flood risk is the primary step towards building a comprehensive flood management strategy for any flood-prone region. A flood risk map serves as an essential tool for the general public, disaster experts, and civic bodies when adopting various mitigation options through assorted structural (e.g., flood storage reservoirs and dikes) and nonstructural (e.g., flood plain zoning, insurance schemes, and policies) measures. In this study, we have quantified hazard and vulnerability components of flood risk through a first-of-its-kind bivariate choropleth Risk-classifier in a holistic framework for two different time scenarios. The dynamics of bivariate flood risk is understood at a decadal scale through identifying the marginal and compound contributions of hazard and vulnerability components. Although the past literature addresses several pathways, minimal efforts have been put into quantifying the degree of risk from a socio-economic perspective. Through this study, we aim to stress the dire need of putting the qualitative socio-economic vulnerability component on the same pedestal as the quantitative hazard component in a flood-risk mapping framework. We chose Jagatsinghpur District (Odisha, India) to demonstrate our framework over two temporal 

a severely flood-prone region due to its geographical location and societal structure. An exhaustive flood modeling platform using a 1D-2D coupled MIKE FLOOD model was established for determining the flood hazard component in terms of floodwater depth ' $d$ ' and tuple of floodwater depth and velocity ' $(d, f)$ '. The other component of flood-risk, vulnerability, was quantified using various socio-economic indicators.

617 One innovative feature of our study is the use of a wide array of 21 relevant socio-economic indicators for finding vulnerability at the smallest administrative level, i.e., at the village level. All these above-mentioned steps led us to eventually propose a Risk-classifier that manifests the individual and compound influence of hazard and vulnerability components on flood-risk through a bivariate choropleth. This innovative idea of the choropleth uses a $5 \times 5$ matrix of 25 different hues to indicate hazard and vulnerability and helps in identifying the level of floodrisk from both these components. The observational results suggested that Scenario-I was dominated by hazard along with hazard-driven and vulnerability-driven risk, while most villages in Scenario-II faced vulnerability-driven risk. A substantial rise in high and very-high risk in Scenario-I due to both hazard and vulnerability was also seen. The very-high risk zones (due to hazard alone or both hazard \& vulnerability) were mostly found in the NW and SE regions of the study area. Although the proposed framework can be applied to any flood-prone region, it will especially be useful for developing and under-developed countries wherein, unfortunately, minimal efforts are invested in flood-data inventory creation.

The identification of flood risk inspires several topics of discussion regarding flood management through a participatory mechanism of policies and technical support systems. In our flood-prone study area, we observed some regions to be risk-influenced by hazard alone, some by vulnerability alone, while some by both. Hence, we need to accordingly shell out 
635 focused flood-management strategies depending upon if flood-risk is being instigated by 636 hazard or vulnerability or both. Rigorous enforcement of policies and uplifting schemes appears to be a standalone solution for locations where vulnerability alone seems capable of causing high risk. On the other hand, in areas predominantly featuring risk arising from the hazard, enhanced structural measures and flood zoning should be exercised. The proposed framework is unified and may be utilized for other flood-prone regions around the globe. Even though we have attempted to build the best possible flood-risk framework for data-scarce regions, it can also be utilized to improve flood analysis of areas with adequate rainfall and streamflow observations. In future studies, gridded radar and satellite-derived rainfall data may be included in the framework as well. In summary, we believe in the potentiality of Flood risk mapping as a promising way forward for building flood management strategies. Its multidisciplinary demeanor calls for a synergistic effort from engineers and social scientists for its successful implementation and thus formulation of informed disaster-managerial decisions. This framework is not limited to identification of flood risk and its change, but can also be extended to study various natural and anthropogenic induced human-environment systems under global environmental change.

\section{Acknowledgements}

652 The work presented here is supported financially by ISRO-IIT(B)-Space Technology Cell (STC) through a sponsored project (No.14ISROC009). The authors sincerely thank the India Meteorological Department (IMD) Pune, for providing at-site hourly rainfall data for the 3 stations considered in the study. The authors also thank National Remote Sensing Centre (NRSC), Hyderabad; Department of Water Resources (DoWR), Govt. of Odisha; and Odisha Space Applications Centre (ORSAC), Odisha, for providing relevant data for carrying out the research. The authors are grateful to NRSC for allowing the access to LiDAR DEM and MIKE 

quality and readability of the manuscript.

\section{References}

1. Abbott, M. B., \& Ionescu, F. (1967). On the numerical computation of nearly horizontal flows. Journal of Hydraulic Research, 5(2), 97-117. https://doi.org/10.1080/00221686709500195

2. Ahilan, S., O'Sullivan, J.J., \& Bruen, M. (2012). Influences on flood frequency distributions in Irish river catchments. Hydrological and Earth System Sciences, 16, 1137-1150. https://doi.org/10.5194/hess-16-1137-2012

3. Ajibade, I., McBean, G., \& Bezner-Kerr, R. (2013). Urban flooding in Lagos, Nigeria: Patterns of vulnerability and resilience among women. Global Environmental Change, 23(6), 1714-1725 https://doi.org/10.1016/j.gloenvcha.2013.08.009

4. Alfieri, L., Bisselink, B., Dottori, F., Naumann, G., Wyser, K., Feyen, L., Roo, A. De, de Roo, A., Salamon, P., Wyser, K., \& Feyen, L. (2017). Earth's Future Global projections of river flood risk in a warmer world. Earth's Future, 5, 171-182. https://doi.org/10.1002/2016EF000485

5. Apel, H., Aronica, G.T., Kreibich, H., \& Thieken, A.H. (2009). Flood risk analyses How detailed do we need to be? Natural Hazards, 49, 79-98. https://doi:10.1007/s11069-008-9277-8

6. Aronica, G. T., Candela, A., Fabio, P., \& Santoro, M. (2012). Estimation of flood inundation probabilities using global hazard indexes based on hydrodynamic variables. Physics and Chemistry of the Earth, Parts A/B/C, 42, 119-129. https://doi: 10.1016/j.pce.2011.04.001

7. Arrighi, C., Pregnolato, M., Dawson, R. J., \& Castelli, F. (2019). Preparedness against mobility disruption by floods. Science of the Total Environment, 654, 1010-1022. https://doi: 10.1016/j.scitotenv.2018.11.191

8. Arrighi, C., Rossi, L., Trasforini, E., Rudari, R., Ferraris, L., Brugioni, M., Franceschini, S. \& Castelli, F. (2018). Quantification of flood risk mitigation benefits: A building-scale damage assessment through the RASOR platform. Journal of environmental management, 207, 92-104 https://doi.org/10.1016/j.jenvman.2017.11.017

9. Balica, S.F., Wright, N.G. \& van der Meulen, F. (2012). A flood vulnerability index for coastal cities and its use in assessing climate change impacts. Natural Hazards, 64, 73105. https://doi:10.1007/s11069-012-0234-1

10. Banker, R. D., Charnes, A., \& Cooper, W. W. (1984). Some models for estimating technical and scale inefficiencies in data envelopment analysis. Management Science, 30(9), 1078-1092. https://doi.org/10.1287/mnsc.30.9.1078

11. Bilskie, M. V., \& Hagen, S. C. (2018). Defining Flood Zone Transitions in LowGradient Coastal Regions. Geophysical Research Letters, 45(6), 2761-2770. https://doi:10.1002/2018GL077524 
12. Bouwer, L. M., Bubeck, P., \& Aerts, J. C. (2010). Changes in future flood risk due to climate and development in a Dutch polder area. Global Environmental Change, 20(3), 463-471 https://doi.org/10.1016/j.gloenvcha.2010.04.002

13. Census of India (2001). Provisional Population Totals, Census of India. Offee of the Registrar General and Census Commissioner, India.

14. Census of India (2011). Provisional Population Totals, Census of India. Office of the Registrar General and Census Commissioner, India.

15. Chen, Q., Xia, J., Falconer, R. A., \& Guo, P. (2018). Further improvement in a criterion for human stability in floodwaters. Journal of Flood Risk Management, e12486. https://doi:10.1111/jfr3.12486

16. Chen, Y., Zhou, H., Zhang, H., Du, G., \& Zhou, J. (2015). Urban flood risk warning under rapid urbanization. Environmental research, 139, 3-10. https://doi: 10.1016/j.envres.2015.02.028.

17. Cozannet, G.L., Garcin, M., Bulteau, T., Mirgon, C., Yates, M.L., Méndez, M., Baills, A., Idier, D. and Oliveros, C. (2013). An AHP-derived method for mapping the physical vulnerability of coastal areas at regional scales. Natural Hazards and Earth System Sciences, 13(5), 1209-1227. https://doi: 10.5194/nhess-13-1209-2013.

18. Dawson, R. J., Ball, T., Werritty, J., Werritty, A., Hall, J. W., \& Roche, N. (2011). Assessing the effectiveness of non-structural flood management measures in the Thames Estuary under conditions of socio-economic and environmental change. Global Environmental Change, 21(2), 628-646 https://doi.org/10.1016/j.gloenvcha.2011.01.013

19. Demir, V., \& Kisi, O. (2016). Flood hazard mapping by using geographic information system and hydraulic model: Mert River, Samsun, Turkey. Advances in Meteorology, 2016 https://doi:10.1155/2016/4891015

20. DiMarco, S. F., \& Reid, R. O. (1998). Characterization of the principal tidal current constituents on the Texas-Louisiana shelf. Journal of Geophysical Research: Oceans, 103(C2), 3093-3109. https://doi.org/10.1029/97JC03289

21. District Emergency Operation Center (2016). District Disaster Management Plan Jagatsinghpur. Jagatsinghpur.

22. DHI (2013). MIKE FLOOD-1D-2D Modelling-User Manual.

23. Domeneghetti, A., Vorogushyn, S., Castellarin, A., Merz, B., \& Brath, A. (2013). Probabilistic flood hazard mapping: effects of uncertain boundary conditions. Hydrology and Earth System Sciences, 17(8), 3127-3140 https://doi:10.5194/hess-17-3127-2013

24. Garcia, M., Peters-Lidard, C. D., \& Goodrich, D. C. (2008). Spatial interpolation of precipitation in a dense gauge network for monsoon storm events in the southwestern United States. Water Resources Research, 44(5), 1-14. https://doi:10.1029/2006WR005788

25. Guhathakurta, P., Sreejith, O. P., \& Menon, P. A. (2011). Impact of climate change on extreme rainfall events and flood risk in India. Journal of earth system science, 120(3), 359

26. Habel, S., Fletcher, C. H., Rotzoll, K., \& El-Kadi, A. I. (2017). Development of a model to simulate groundwater inundation induced by sea-level rise and high tides in Honolulu, Hawaii. Water research, 114, 122-134 https://doi: 10.1016/j.watres.2017.02.035

27. Hallegatte, S., Green, C., Nicholls, R. J., \& Corfee-Morlot, J. (2013). Future flood losses in major coastal cities. Nature climate change, 3(9), 802 https://doi:10.1038/nclimate1979 
28. Halsnæs, K. and Kaspersen, P. S. (2014) 'Risikovurdering for oversvømmelser i byer', Vand \& Jord, 21(3).

29. Hammond, M. J., Chen, A. S., Djordjević, S., Butler, D., \& Mark, O. (2015). Urban flood impact assessment: A state-of-the-art review. Urban Water Journal, 12(1), 14-29. https://10.1080/1573062X.2013.857421.

30. Huang, C., \& Huang, Y. (2018). An information diffusion technique to assess integrated hazard risks. Environmental research, 161, 104-113 https://doi.org/10.1016/j.envres.2017.10.037.

31. Huang, D., Zhang, R., Huo, Z., Mao, F., Youhao, E., \& Zheng, W. (2012). An assessment of multidimensional flood vulnerability at the provincial scale in China based on the DEA method. Natural hazards, 64(2), 1575-1586. https://doi:10.1007/s11069-012-0323-1

32. Hunter, J. R., Woodworth, P. L., Wahl, T., \& Nicholls, R. J. (2017). Using global tide gauge data to validate and improve the representation of extreme sea levels in flood impact studies. Global and Planetary Change, 156, 34-45. https://doi:10.1016/j.gloplacha.2017.06.007

33. Kadam, P., \& Sen, D. (2012). Flood inundation simulation in Ajoy River using MIKEFLOOD. ISH Journal of Hydraulic Engineering, 18(2), 129-141 https://doi:10.1080/09715010.2012.695449

34. Karmakar, S., Simonovic, S. P., Peck, A., \& Black, J. (2010). An information system for risk-vulnerability assessment to flood. Journal of Geographic Information System, 2(03), 129. https://doi:10.4236/jgis.2010.23020

35. Kelman, I., \& Spence, R. (2004). An overview of flood actions on buildings. Engineering Geology, 73(3-4), 297-309. https://doi: 10.1016/j.enggeo.2004.01.010

36. Knighton, J., Steinschneider, S., \& Walter, M. T. (2017). A Vulnerability-Based, Bottom-up Assessment of Future Riverine Flood Risk Using a Modified Peaks-OverThreshold Approach and a Physically Based Hydrologic Model. Water Resources Research, 53(12), 10043-10064 https://doi:10.1002/2017WR021036

37. Koks, E. E., Jongman, B., Husby, T. G., \& Botzen, W. J. (2015). Combining hazard, exposure and social vulnerability to provide lessons for flood risk management. Environmental Science \& Policy, 47, 42-52. https://doi:10.1016/j.envsci.2014.10.013

38. Kourgialas, N. N., \& Karatzas, G. P. (2017). A national scale flood hazard mapping methodology: The case of Greece-Protection and adaptation policy approaches. Science of the Total Environment, 601, 441-452 https://doi:10.1016/j.scitotenv.2017.05.197

39. Kreibich, H., Piroth, K., Seifert, I., Maiwald, H., Kunert, U., Schwarz, J., Merz, B. \& Thieken, A.H., 2009. Is flow velocity a significant parameter in flood damage modelling?,9,1679-1692 https://doi.org/10.5194/nhess-9-1679-2009

40. Kubal, C., Haase, D., Meyer, V., \& Scheuer, S. (2009). Integrated urban flood risk assessment-adapting a multicriteria approach to a city. Natural hazards and earth system sciences, 9(6), 1881-1895 https://doi.org/10.5194/nhess-9-1881-2009

41. Lee, G., Jun, K. S., \& Chung, E. S. (2014). Robust spatial flood vulnerability assessment for Han River using fuzzy TOPSIS with $\alpha$-cut level set. Expert Systems with Applications, 41(2), 644-654. https://doi:10.1016/j.eswa.2013.07.089

42. Li, C. H., Li, N., Wu, L. C., \& Hu, A. J. (2013). A relative vulnerability estimation of flood disaster using data envelopment analysis in the Dongting Lake region of Hunan. Natural Hazards and Earth System Sciences, 13(7), 1723-1734. https://doi:10.5194/nhess-13-1723-2013 
43. Lyu, H. M., Sun, W. J., Shen, S. L., \& Arulrajah, A. (2018). Flood risk assessment in metro systems of mega-cities using a GIS-based modeling approach. Science of the Total Environment, 626, 1012-1025. https://doi.org/10.1016/j.scitotenv.2018.01.138

44. Mardani, A., Zavadskas, E. K., Streimikiene, D., Jusoh, A., \& Khoshnoudi, M. (2017). A comprehensive review of data envelopment analysis (DEA) approach in energy efficiency. Renewable and Sustainable Energy Reviews, 70, 1298-1322 https://doi:10.1016/j.rser.2016.12.030

45. Mani, P., Chatterjee, C., \& Kumar, R. (2014). Flood hazard assessment with multiparameter approach derived from coupled 1D and 2D hydrodynamic flow model. Natural hazards, 70(2), 1553-1574 https://doi:10.1007/s11069-013-0891-8

46. Merz, B., Kreibich, H., Schwarze, R., \& Thieken, A. (2010). Review article" Assessment of economic flood damage". Natural Hazards and Earth System Sciences, 10(8), 1697-1724 https://doi:10.5194/nhess-10-1697-2010

47. Meyer, V., Scheuer, S., \& Haase, D. (2009). A multicriteria approach for flood risk mapping exemplified at the Mulde river, Germany. Natural hazards, 48(1), 17-39. https://doi:10.1007/s11069-008-9244-4

48. Mishra, S., Mazumdar, S., \& Suar, D. (2010). Place attachment and flood preparedness. Journal of environmental psychology, 30(2), 187-197 https://doi:10.1016/j.jenvp.2009.11.005

49. Mugume, S. N., Gomez, D. E., Fu, G., Farmani, R., \& Butler, D. (2015). A global analysis approach for investigating structural resilience in urban drainage systems. Water Research, 81, 15-26 https://doi:10.1016/j.watres.2015.05.030

50. Muis, S., Güneralp, B., Jongman, B., Aerts, J. C., \& Ward, P. J. (2015). Flood risk and adaptation strategies under climate change and urban expansion: A probabilistic analysis using global data. Science of the Total Environment, 538, 445-457 https://doi:10.1016/j.scitotenv.2015.08.068

51. Mustafa, A., Bruwier, M., Archambeau, P., Erpicum, S., Pirotton, M., Dewals, B., \& Teller, J. (2018). Effects of spatial planning on future flood risks in urban environments. Journal of environmental management, 225, 193-204 https://doi.org/10.1016/j.jenvman.2018.07.090

52. Mohanty, M. P., Sherly, M. A., Karmakar, S., \& Ghosh, S. (2018). Regionalized Design Rainfall Estimation: an Appraisal of Inundation Mapping for Flood Management Under Data-Scarce Situations. Water Resources Management, 32, 4725-4746 https://doi:10.1007/s11269-018-2080-8

53. Mohapatra, P. K., \& Singh, R. D. (2003). Flood management in India. In Flood Problem and Management in South Asia Springer, Dordrecht, 131-143.

54. Moon, J., Flannery, W., \& Revez, A. (2017). Discourse and practice of participatory flood risk management in Belfast, UK. Land Use Policy, 63, 408-417 https://doi:10.1016/j.landusepol.2017.01.037

55. Morrison, J. E., \& Smith, J. A. (2002). Stochastic modeling of flood peaks using the generalized extreme value distribution. Water Resources Research, 38(12) https://doi:10.1029/2001WR000502

56. Ntajal, J., Lamptey, B. L., Mahamadou, I. B., \& Nyarko, B. K. (2017). Flood disaster risk mapping in the Lower Mono River Basin in Togo, West Africa. International journal of disaster risk reduction, 23, 93-103 https://doi:10.1016/j.ijdrr.2017.03.015

57. Olesen, L., Löwe, R., Arnbjerg-Nielsen, K. (2017). Flood Damage Assessment Literature review and recommended procedure. Melbourne, Australia.

58. Overeem, A., Buishand, T. A., \& Holleman, I. (2009). Extreme rainfall analysis and estimation of depth-duration-frequency curves using weather radar. Water resources 
59. Papaioannou, G., Loukas, A., Vasiliades, L., \& Aronica, G. T. (2016). Flood inundation mapping sensitivity to riverine spatial resolution and modelling approach. Natural Hazards, 83(1), 117-132. https://doi:10.1007/s11069-016-2382-1

60. Patro, S., Chatterjee, C., Singh, R., \& Raghuwanshi, N. S. (2009). Hydrodynamic modelling of a large flood-prone river system in India with limited data. Hydrological Processes: An International Journal, 23(19), 2774-2791. https://doi:10.1002/hyp.7375

61. Pawlowicz, R., Beardsley, B., \& Lentz, S. (2002). Classical tidal harmonic analysis including error estimates in MATLAB using T_TIDE. Computers \& Geosciences, 28(8), 929-937 https://doi:10.1016/S0098-3004(02)00013-4

62. Qiang, Y. (2019). Disparities of population exposed to flood hazards in the United States. Journal of environmental management, 232, 295-304 https://doi.org/10.1016/j.jenvman.2018.11.039

63. Quinn, N., Lewis, M., Wadey, M. P., \& Haigh, I. D. (2014). Assessing the temporal variability in extreme storm-tide time series for coastal flood risk assessment. Journal of Geophysical Research: Oceans, 119(8), 4983-4998. https://doi:10.1002/2014JC010197

64. Ray, N. S. (2006). Caste, class and gender: multiple disasters and women-headed households in an Oriya village (Doctoral dissertation, University of Warwick).

65. Retchless, D. P., \& Brewer, C. A. (2016). Guidance for representing uncertainty on global temperature change maps. International Journal of Climatology, 36(3), 11431159. https://doi:10.1002/joc. 4408

66. Rodriguez-Llanes, J. M., Ranjan-Dash, S., Mukhopadhyay, A., \& Guha-Sapir, D. (2016). Flood-exposure is associated with higher prevalence of child Undernutrition in rural Eastern India. International journal of environmental research and public health, 13(2), 210. https://doi:10.3390/ijerph13020210

67. Russo, B., Gómez, M., \& Macchione, F. (2013). Pedestrian hazard criteria for flooded urban areas. Natural hazards, 69(1), 251-265 https://doi: 10.1007/s11069-013-0702-2.

68. Saein, A. F., \& Saen, R. F. (2012). Assessment of the site effect vulnerability within urban regions by data envelopment analysis: a case study in Iran. Computers \& geosciences, 48, 280-288 https://doi:10.1016/j.cageo.2012.01.018

69. Sahoo, B., \& Bhaskaran, P. K. (2018). Multi-hazard risk assessment of coastal vulnerability from tropical cyclones-A GIS based approach for the Odisha coast. Journal of environmental management, 206, 1166-1178 https://doi:10.1016/j.jenvman.2017.10.075

70. Samantaray, D., Chatterjee, C., Singh, R., Gupta, P. K., \& Panigrahy, S. (2015). Flood risk modeling for optimal rice planning for delta region of Mahanadi river basin in India. Natural Hazards, 76(1), 347-372 https://doi:10.1007/s11069-014-1493-9

71. Scheuer, S., Haase, D., \& Meyer, V. (2011). Exploring multicriteria flood vulnerability by integrating economic, social and ecological dimensions of flood risk and coping capacity: from a starting point view towards an end point view of vulnerability. Natural Hazards, 58(2), 731-751. https://doi:10.1007/s11069-010-9666-7

72. Schubert, J. E., \& Sanders, B. F. (2012). Building treatments for urban flood inundation models and implications for predictive skill and modeling efficiency. Advances in Water Resources, 41, 49-64 https://doi:10.1016/j.advwatres.2012.02.012

73. Şen, O., \& Kahya, E. (2017). Determination of flood risk: A case study in the rainiest city of Turkey. Environmental Modelling \& Software, 93, 296-309. https://doi:10.1016/j.envsoft.2017.03.030

74. Shao, W., Xian, S., Lin, N., Kunreuther, H., Jackson, N., \& Goidel, K. (2016). Understanding the effects of past flood events and perceived and estimated flood risks 
on individuals' voluntary flood insurance purchase behaviour. Water research, 108, 391-400. https://doi:10.1016/j.watres.2016.11.021

75. Shao, W., Xian, S., Lin, N., \& Small, M. J. (2017). A sequential model to link contextual risk, perception and public support for flood adaptation policy. Water research, 122, 216-22. https://doi: 10.1016/j.watres.2017.05.072

76. Sharma, S., Isik, S., Srivastava, P., \& Kalin, L. (2012). Deriving spatially distributed precipitation data using the artificial neural network and multilinear regression models. Journal of Hydrologic Engineering, 18(2), 194-205. https://doi:10.1061/(ASCE)HE.1943-5584.0000617

77. Sherly, M. A., Karmakar, S., Parthasarathy, D., Chan, T., \& Rau, C. (2015). Disaster vulnerability mapping for a densely populated coastal urban area: An application to Mumbai, India. Annals of the Association of American Geographers, 105(6), 11981220. https://doi:10.1080/00045608.2015.1072792

78. Speich, M. J., Bernhard, L., Teuling, A. J., \& Zappa, M. (2015). Application of bivariate mapping for hydrological classification and analysis of temporal change and scale effects in Switzerland. Journal of Hydrology, 523, 804-821. https://doi:10.1016/j.jhydrol.2015.01.086

79. Thorndahl, S., \& Willems, P. (2008). Probabilistic modelling of overflow, surcharge and flooding in urban drainage using the first-order reliability method and parameterization of local rain series. Water research, 42(1-2), 455-466 https://doi:10.1016/j.watres.2007.07.038

80. Tingsanchali, T., \& Karim, M. F. (2005). Flood hazard and risk analysis in the southwest region of Bangladesh. Hydrological Processes: An International Journal, 19(10), 2055-2069 https://doi:10.1002/hyp.5666

81. Turner, B.L., Kasperson, R.E., Matson, P.A., McCarthy, J.J., Corell, R.W., Christensen, L., Eckley, N., Kasperson, J.X., Luers, A., Martello, M.L. and Polsky, C. (2003). A framework for vulnerability analysis in sustainability science. Proceedings of the national academy of sciences, 100(14), 8074-8079. https://doi:10.1073/pnas.1231335100

82. UNISDR (2009) Terminology on disaster risk reduction. http://www.unisdr.org/eng/terminology/UNISDR-terminology-2009eng.pdf

83. Usón, T. J., Klonner, C., \& Höfle, B. (2016). Using participatory geographic approaches for urban flood risk in Santiago de Chile: Insights from a governance analysis. Environmental Science \& Policy, 66, 62-72. https://doi:10.1016/j.envsci.2016.08.002

84. Van Alphen, J., Martini, F., Loat, R., Slomp, R., \& Passchier, R. (2009). Flood risk mapping in Europe, experiences and best practices. Journal of Flood Risk Management, 2(4), 285-292. https://doi:10.1111/j.1753-318X.2009.01045.X

85. Vojinovic, Z., \& Tutulic, D. (2009). On the use of 1D and coupled 1D-2D modelling approaches for assessment of flood damage in urban areas. Urban water journal, 6(3), 183-199. https://doi:10.1080/15730620802566877

86. Wang, Y., Yang, H., Yang, D., Qin, Y., Gao, B., \& Cong, Z. (2017). Spatial interpolation of daily precipitation in a high mountainous watershed based on gauge observations and a regional climate model simulation. Journal of Hydrometeorology, 18(3), 845-862. https://doi:10.1175/JHM-D-16-0089.1

87. Ward, P. J., Jongman, B., Weiland, F. S., Bouwman, A., van Beek, R., Bierkens, M. F., Ligtvoet, W., \& Winsemius, H. C. (2013). Assessing flood risk at the global scale: model setup, results, and sensitivity. Environmental research letters, 8(4), 044019 https://doi:10.1088/1748-9326/8/4/044019 
88. Warren, I. R., \& Bach, H. (1992). MIKE 21: a modelling system for estuaries, coastal waters and seas. Environmental Software, 7(4), 229-240. https://doi:10.1016/02669838(92)90006-P

89. Winsemius, H. C., Van Beek, L. P. H., Jongman, B., Ward, P. J., \& Bouwman, A. (2013). A framework for global river flood risk assessments. Hydrology and Earth system sciences, 17, 1871-1892. https://doi:10.5194/hess-17-1871-2013

90. Worqlul, A. W., Yen, H., Collick, A. S., Tilahun, S. A., Langan, S., \& Steenhuis, T. S. (2017). Evaluation of CFSR, TMPA 3B42 and ground-based rainfall data as input for hydrological models, in data-scarce regions: The upper Blue Nile Basin, Ethiopia. Catena, 152, 242-251. https://doi:10.1016/j.catena.2017.01.019

91. Xia, J., Falconer, R. A., Lin, B., \& Tan, G. (2011). Numerical assessment of flood hazard risk to people and vehicles in flash floods. Environmental Modelling \& Software, 26(8), 987-998. https://doi:10.1016/j.envsoft.2011.02.017

92. Zagonari, F., \& Rossi, C. (2013). A heterogeneous multi-criteria multi-expert decisionsupport system for scoring combinations of flood mitigation and recovery

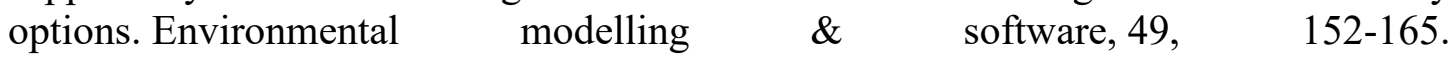
https://doi:10.1016/j.envsoft.2013.08.004

93. Zhong, S., Yang, L., Toloo, S., Wang, Z., Tong, S., Sun, X., Crompton, D., FitzGerald, G. and Huang, C. (2018). The long-term physical and psychological health impacts of flooding: a systematic mapping. Science of the Total Environment, 626, 165-194. https://doi.org/10.1016/j.scitotenv.2018.01.041 